\title{
A new Disruption Mitigation Valve (DMV) and gas flow in guiding tubes of different diameter
}

\author{
K.H. Finken ${ }^{1}$, M. Lehnen ${ }^{1}$, S.A. Bozhenkov ${ }^{2}$ \\ ${ }^{1}$ Institute for Energy Research - Plasma Physics, Forschungzentrum Jülich GmbH, \\ EURATOM-Association, Trilateral Euregio Cluster, D-52425 Juelich, Germany \\ ${ }^{2}$ Max-Planck-Institut für Plasmaphysik, D-17491 Greifswald, Germany
}

\begin{abstract}
A new disruption mitigation valve, the DMV-30, has been developed and tested. The orifice output area of the valve is a factor of 2.4 and 12.25 times larger than that of its predecessors, DMV 20 and DMV 10, and the gas reservoir amounts to $1.3 \mathrm{l}$ while the older version used at JET had only $0.65 \mathrm{l}$. The coil which provides the magnetic field pulse for the activation of the piston by an eddy current is outside of the working gas volume such that now all gas volumes are now made of stainless steel. The valve has the advantages of the previous developments: it is robust and reproducible, opens fully within three milliseconds and releases $50 \%$ of the gas within about $5 \mathrm{~ms}(\mathrm{He})$ to $10 \mathrm{~ms}(\mathrm{Ar})$. The valve is attached subsequently to two different guiding tubes, one with an inner diameter of $38 \mathrm{~mm}$ as used presently at JET and one with $102 \mathrm{~mm}$ inner diameter; an aim of this article is the analysis of the gas flows for the different diameters. The front of the gas pulse propagates with a Mach number of about 2.5 through the tubes, independent of the two diameters. This high speed agrees with theoretical expectations of a flow expansion of a half infinite tube in vacuum. In the quasi-stationary phase of the expansion, the gas flows with about sound speed in the $102 \mathrm{~mm}$ tube and with about half of the sound speed in the $38 \mathrm{~mm}$ tube.
\end{abstract}

\section{Introduction}

The mitigation of thermal loads and mechanical stresses during disruptions is an urgent task to be solved for ITER. Extreme loads are already an issue for present day machines. For ITER the mitigation of these loads is mandatory to ensure the projected lifetime of the vessel structures and plasma facing components. The threat stems from the high thermal energy 
stored in the plasma and the magnetic energy carried by the plasma current. A review about disruptions, their causes, their effects and schemes of the mitigation of their effects is treated in a special issue of Nucl. Fusion on the "ITER Physics Basis" [1,2,3] as well as in the review in [4]. The detrimental effects of disruptions are the excessive heat flux during the energy quench $[5,6,7,8,9]$, the generation of runaway electrons [10] in the current decay phase [11], halo currents of the cold disrupted plasma which partially flows at the plasma edge and partially in the vessel, the enormous forces resulting from halo currents, the loading of the walls and rearrangement of the impurities which often inhibit the start of the following discharge.

Disruptions occur because either a boundary of stable plasma operation is passed or due to a failure of control circuits. The disruptions which slowly pass a stability boundary often provide enough warning time prior to the disruption. This time can be used to start a mitigation process such as rapid and massive gas injection by a special "disruption mitigation valve” (DMV) [12,13,14,15,16,17,18,19,20,21,22], by killer pellets [23], by liquid jets [24], or by external helical fields [25, 26]. During this warning time, neural networks [27,28,29] have been trained to find stable and unstable operation conditions and are applied to warn for a coming disruption. Neo-classical tearing [30,31] modes proceed typically $\beta$-limit disruption, a mixture of modes [32], in particular the $m / n=3 / 2$ and $2 / 1$ modes are observed before most other disruptions.

For the healing of plasma modes, experiments with additional heating $[33,34,35]$ have been performed. The heating is of particular interest for plasma states which are close to a radiative collapse, e.g. near the density limit or at increased impurity levels. Heating methods which transfer a toroidal force to the plasma such as tangential NBI have the additional advantage that the dangerous mode locking is avoided. The mode locking due to error fields becomes an increasingly serious problem with the increased size of the fusion devices [36,37]. For a reactor only very small error fields are tolerable without additional means.

The following article is a continuation of our previous efforts on optimizing a disruption mitigation valve and to measure the flow in a guiding tube between the valve and the vessel $[38,39,40]$. The different devices have different requirements on the amount of gas needed for the mitigation. The amount of gas needed also depends on the type of load to be mitigated. The highest gas amount is needed to suppress the avalanche multiplication of runaway electrons, whereas mitigation of forces and of heat loads might be achieved at significantly smaller amounts. The required amount for unconditional runaway suppression in ITER is 
estimated to be $100-500 \mathrm{kPam}^{3}$, depending on gas species [41]. The highest fuelling efficiency is achieved, if the valve releases the gas into the plasma edge before the thermal quench [20]. Unfortunately, the time between the arrival of the gas front at the plasma surface and thermal quench decreases if the arriving gas flow increases. The thermal quench during massive gas injection is initiated when the cooling front reaches the $\mathrm{q}=2$ surface. The transient cooling time may be in the low millisecond range such that a good DMV has to provide a sharp gas pulse. However, a fast valve is not sufficient; the transfer tube between DMV and plasma leads to additional delay in gas delivery and to a broadening of the gas pulse. In the previous JET campaign, the guiding tube had a diameter of $38 \mathrm{~mm}$ and a length of about $4 \mathrm{~m}$. The disruption is observed 7 to $15 \mathrm{~ms}$ after the trigger of the valve, depending on the gas species and loading pressure of the valve [22]. The geometry of the guiding tube has strong impact on whether the mitigation goals in ITER can be met by this technique; a characterisation of the flow in the guiding tube is therefore an essential task.

The article treats the new DMV-30 which has an orifice of $28 \mathrm{~mm}$, in contrast to the two previous developments with output openings of $10 \mathrm{~mm}$ (DMV-10) and $18 \mathrm{~mm}$ (DMV-20) [40]. We then present the resulting gas flow in two tubes of different diameter. The gas flow is measured at three locations along the tube by a new - commercial - interferometer and by Pitot tubes. The questions of special interest are about the delay of the gas front arrival time at the different locations, about the rise time of the front at the different locations, about the front velocity and about the average pulse velocity. Topics to be treated in the following are the set-up, the characterisation of the new valve including some estimates, a description of the new interferometer and its properties, the Pitot tube for determining the gas flow speed, and a depiction of the gas flow in the two guiding tubes.

\section{The set up}

The valve and gas line set-up have been arranged similar to the present JET design of the injection system. A sketch of the experimental set-up is shown in Figure 1. The gas is filled into the DMV-30 by control valves which are not shown. The pressure in the working gas chamber and in the closure gas chamber is measured with pressure transducers (see below). The valve is opened after a trigger signal by the activation of a power supply; the released gas flows along the guiding tube of a length of $4100 \mathrm{~mm}$ to a recipient of $300 \mathrm{l}$ volume where the initial and end pressures are measured by a 2 bar Baratron. The volume is pumped down by a roots blower before the activation of the valve. At the distances of $297 \mathrm{~mm}, 2337 \mathrm{~mm}$ and $4192 \mathrm{~mm}$ from the seal of the valve, windows are placed into the guiding tubes which allow 
an interferometric measurement of the optical path from which the gas density can be calculated. Between the windows two concrete blocks of $60 \mathrm{~kg}$ weight each are attached in order to enhance inertia and to reduce the oscillations of the tube. At the end of the tube we also measure the flow by a Pitot tube. We are using two different tube diameters, namely 38 $\mathrm{mm}$ and $102 \mathrm{~mm}$. We now discuss the new DMV and the diagnostics in more detail.

\subsection{The valve}

The DMV-30 is a further development of the previous types and it is based on the same principles $[38,40]$. A sketch of its design is shown in Fig. 2. The active parts of the valve are a coil and a piston. The coil $(\mathrm{L}=150 \mu \mathrm{H})$ is activated by a power supply (Fug company: HCK $100-2000 \mathrm{MOD}$ ) which discharges a capacitor of $\mathrm{C}=400 \mu \mathrm{F}$ at a voltage of typically $\mathrm{U}=$ $1.7 \mathrm{kV}$ via a thyristor. The coil current induces an eddy current in the mushroom part of the piston which transfers a force and accelerates the stem away from the coil. The piston is fabricated out of aluminium which is light, has a high electrical conductivity and is not ferromagnetic, so that magnetic fields near a tokamak have no influence on the valve.

The piston motion opens the gas reservoir towards the tokamak. As compared to its predecessors the valve is larger in size; its gas reservoir amounts to $1.3 \mathrm{l}$ as compared to $0.65 \mathrm{l}$ as we had used previously for JET; the filling pressure is limited to $40 \mathrm{bar}$. At full pressure, the valve releases slightly more than 40 bar*l.

After its activation, the mushroom part of the piston compresses the gas in the closure volume until the pressure balance between closing and working chamber allows closing. This gas cushion acts as a spring and provides nearly an elastic reflection of the piston. The gas pressure in the closure volume guarantees that the piston closes under all conditions. Since the Viton gaskets at the piston shaft (which separates the working volume from the closure volume) and at the valve exit have both an inner diameter of $30 \mathrm{~mm}$, the piston is force free if the pressure at the exit (usually vacuum) equals the pressure in the closing chamber. In order to press the Viton O-ring at the valve outlet such that the valve is leak tight, a pressure in the closing volume of at least 1.5 bar is required. If the valve is initially not closed, a friction force has to be overcome in addition to move the piston to the closed state. The experiments show that a pressure of 3 bar in the closure volume is sufficient for this. This pressure has been kept constant during our tests. As closing gas we used Argon. The main differences to the previous design are marked with the letters " $A$ " and " $B$ ” in Fig. 2. Part "A" refers to the 
penetration of the magnetic field from the coil through the metal casing toward the piston and in part " $\mathrm{B}$ " we discuss the expected output of the gas from the valve.

\subsection{A) Field penetration}

In the previous valve designs, the coil was integrated directly into the closure volume. The coil was manufactured of a copper sheet, isolated by a glass fibre mat and impregnated with epoxy. The new DMV-30 has a full metal casing machined of SS. Due to pressure forces and related safety regulations a wall thickness of at least $5 \mathrm{~mm}$ is required for the coil housing. The question arises whether this wall thickness shields too much the eddy currents and worsens the previously very short activation time of the valve.

Key parameters for the electrical circuit are the coil voltage and the coil current which are displayed in Fig. 3a and 3b. The coil voltage is applied to a quarter of a LC period which is then truncated by the electrical circuit. The coil current is slightly longer than the quarter of the period, but it starts to oscillate when the voltage reaches zero and decays to zero. The oscillation is clearly linked to the voltage passing zero and not to a change in the inductivity as may result from a movement of the piston. The system frequency derived from the quarter of the period amounts to $650 \mathrm{~Hz}$ and agrees well with the expectations of an LC - circuit, which means that the external inductivity of the cable can be neglected.

The circuit frequency is related to the skin penetration of the electromagnetic field through a metal by:

$$
\delta=\sqrt{\frac{1}{\mu_{0} \sigma \omega}}
$$

where $\delta$ is the penetration depth, $\sigma$ the electrical conductivity and $\omega$ the angular frequency. The electrical conductivity amounts for stainless steal (SS, casing) to $\sigma=1.36 * 10^{6} \mathrm{~S} / \mathrm{m}$ and for $\mathrm{Al}$ (piston) to $\sigma=3.6610^{7} \mathrm{~S} / \mathrm{m}$. For the given frequency this yields a penetration depth of $12 \mathrm{~mm}$ for SS and $2.3 \mathrm{~mm}$ for Al. This shows that the field penetrates easily through the SS of the casing. Since the mushroom part of the piston is about $10 \mathrm{~mm}$ thick, the field is well accepted in the $\mathrm{Al}$ for creating the required eddy current. If one defines $T$ as the time of a quarter period of a sinusoidal oscillation, then the $5 \mathrm{~mm} \mathrm{SS}$ casing is penetrated within $T=$ $0.06 \mathrm{~ms}$ and the $10 \mathrm{~mm}$ piston requires $T=7.7 \mathrm{~ms}$. These values show that the SS casing is 
no restriction for the fast operation of the valve; we measure for all valves a first gas release after $0.1 \mathrm{~ms}$, which is the first data point after the trigger.

\subsection{B) Piston Dynamics}

In order to model the valve performance we have measured the axial motion of the piston by a fast camera. For the measurement we have added a $20 \mathrm{~cm}$ long pin to the piston. The camera detects the motion of the piston through the observation window which otherwise is used by the interferometer. The motion depends on the pressure in the closure as well as in the injection volume and on the applied voltage/current. Fig. 4 shows the axial motion for DMV30 as a function of time for different pressure in the injection volume and a constant pressure of 2 bar in the closure volume. The valve starts to open after about $0.5 \mathrm{~ms}$. The maximum free path of the piston is $65 \mathrm{~mm}$. The area which limits the gas flow depends on the opening distance $\Delta \mathrm{x}$ of the piston and is given by $\mathrm{A}=2 \pi^{*} \mathrm{r}^{*} \Delta \mathrm{x}$, where $\mathrm{r}$ is the radius of the orifice. The maximum achievable area is given by the area of the orifice itself. Thus, the valve is fully open for $\Delta x=r / 2$, which is indicated by the dashed line in figure 4. After full opening, the remaining pressure in the injection volume leads to a further acceleration of the piston for the high pressure cases. However, this has no impact on the gas flow because the outflow area is not increased anymore. The time to fully open the valve is given in figure 5 as function of the applied voltage. This time varies between about $5 \mathrm{~ms}$ at low voltage and $2.5 \mathrm{~ms}$ at high voltage. For the gas flow analysis in section 3 we kept the voltage constant at $1.7 \mathrm{kV}$. A dependence of this time on the gas species in the closing volume was not observed.

\subsection{The interferometer}

The measurement of the density of the flow is performed by interferometry, similarly as discussed in our previous publication. We use the commercial type "ZLM 700" from the company “Laser Interferometer Jenaer Meßtechnik” (Germany); it is a two wavelength HeNeinterferometer.

The big advantage of a commercial system is that the programmes are well developed for deriving the optical path or velocity. The interferometer is laid out up to a velocity of $10 \mathrm{~m} / \mathrm{s}$. However, our experiments show that the high speed measurement of a machine is different from the flow measurement. The maximal useable change of the optical path is about 10 $\mathrm{mm} / \mathrm{s}$, which is three orders of magnitude less. Most likely, the turbulence limits the range of 
the application of the interferometer. Nevertheless, the chosen commercial interferometer can measure about 10 times higher changes of the optical path than our Michelson one and is therefore used for this set of measurements.

The set-up of the commercial interferometer is shown in Fig. 6. The set-up differs significantly from the "standard" set-up where two laser beams with a separation of about 1 $\mathrm{cm}$ are used. Here only one beam, which in addition is coupled out at point A and transferred to the PC via an optical fibre cable, is used. The two wavelengths of the laser have different polarizations and are mixed in PC where the frequency shift determines the optical path. Nevertheless, the two wavelengths do not provide an absolute length such that the measurement is also plagued by interferometic jumps, in particular during the highly turbulent phase of the density pulse front. The sampling frequency of the data acquisition is $10 \mathrm{kHz}$.

The interferometer was calibrated by filling the chamber with the gases $\mathrm{He}, \mathrm{Ne}$, Ar and air. The venting pressure versus the optical distance measured by the interferometer is shown in Fig. 7 for the Ar calibration. The pressure is measured by a 2 bar Baratron head. As expected the dependence is linear; the same is found for the other gases.

During the flow measurements, three different types of disturbances of the interferometric signal are observed.

- The first disturbances result from interferometric fringe jumps. An example is shown in Fig. 8a for an Ar filling pressure of 15 bar measured at the middle location. Three gas shots have been performed with identical settings, indicated by different colors. The signal rises sharply after a short delay (flight time of the gas) and decays at a slower rate after the maximum. The signal reaches a nonzero stationary value after $200 \mathrm{~ms}$. Obviously, the signal has lost some fringes during the steep front of the pressure front. We correct therefore the signal by assuming a linear rate of fringe skips during the rising phase. The resulting signals are shown in Fig. 8b. After the correction, the three gas shots show good reproducibility. The good reproducibility is of course not the only criterion to justify the correction; only after the correction all other data derived from the optical path become self consistent such as e.g. the amplitudes shown in Fig. 14 to 16.

- A second type of disturbance is observed only at the entrance window and only with the 38 mm tube. Here the signal does not reach its maximum but shows a dip between $5 \mathrm{~ms}$ and 10 ms. Fig. 9 shows the signal of He at 35 bar after performing the correction of the fringe 
jumps. The origin of this phenomenon is unclear. The fast camera observations show that the dip does not result from an intermediate closure of the valve. The dip occurs for all loading pressures of the valve. As mentioned before, we have added a nearly $20 \mathrm{~cm}$ long and $5 \mathrm{~mm}$ thick pin to the piston for camera observations. Strangely enough, with adding the pin, the dip disappeared as one can see in Fig. 10. The only other modification is that the measurement position of the interferometer has been moved by about $10 \mathrm{~cm}$ further away from the valve. Since we cannot interpret the dip, we do not correct it.

- The third type of disturbance results from mechanical oscillations imposed by the flow. This effect is important only for the $102 \mathrm{~mm}$ tube at the end window. For this condition the flow transports a high momentum to the $300 \mathrm{l}$ volume. The oscillation is excited by the impact of the gas flow and is shown in Fig. 11. The frequency of the oscillation is relatively low. The black curve shows a possible correction of this oscillation. The other windows are not disturbed by mechanical oscillations, probably because of the stabilizing $60 \mathrm{~kg}$ concrete blocks (see figure 1). For the $38 \mathrm{~mm}$ i.d. tube oscillations are not observed.

\subsection{Pitot tube measurements}

Previously [40],the flow of the gas in the guiding tube was determined from a) the time of flight of the foot of the pulse, the middle of the rising pulse and the top and b) from particle balance. Now, in addition, another method is used. Namely, measurements of the dynamic pressure of the flow have been performed from which the velocity can be derived in the quasisationary tail of the gas pulse. To measure the dynamic pressure the Pitot tube shown in Fig. 12 is used. The Pitot tube consists of a $4 \mathrm{~mm}$ tube bent by $90^{\circ}$ at the lower end such that it is directed against the gas flow direction. The tube ends into a volume of a few $\mathrm{cm}^{3}$ accessible via two windows. The gas density in the volume has been measured by the interferometer. The Pitot tube is attached to the guiding tube via a CF-flange. In order to reduce flow turbulences as much as possible, the port is filled with an aluminium block which ends in the radius of the wall of the guiding tube.

The Pitot tube measures the dynamic pressure of the flow which is

$$
p_{\text {pitot }}=m \cdot n_{\text {flow }} \cdot v_{\text {flow }}(t)^{2}=n_{\text {Pitot }} k T_{\text {Pitot }}
$$

Here $m$ is the atomic mass, $n$ the density, $k$ the Boltzmann constant and $T$ the gas temperature. We assume that the temperature in the Pitot tube is the same as in the valve; The temperature 
may drop initially when the gas is accelerated in the valve nozzle but since the gas is stopped in the Pitot tube again, the temperature in the Pitot volume gains back its initial value, if the flow is adiabatic, i.e. subsonic.

The time constant of the Pitot tube is given by $\tau=V / C$ where $V$ is the volume and $C$ the conductance of the Pitot tube. The volume amounts to about $3 \mathrm{~cm}^{3}$ and the upper limit for the conductance is the tube cross section time sound velocity. The resulting lower limit of the Pitot device amounts to about $\tau=1 \mathrm{~ms}$.

\section{The gas flow characterisation}

The modelling of the valve in Fig. 7 proposes that the release of the gas has a sharp rise followed by an exponential decay of the density. This trend is indeed observed at the three locations of observation. Examples of the pulse shape of the density as a function of time are shown in Fig. 13 for Ar with filling pressure of 30 bar; the measurement is taken at the middle of the guiding tube. Fig. 13a shows data for the $38 \mathrm{~mm}$ guiding tube and Fig. 13b for the 102 mm tube. It is obvious that the pulse in the $102 \mathrm{~mm}$ tube is substantially shorter than that in the $38 \mathrm{~mm}$ tube and has an amplitude almost an order of magnitude smaller. The main reason for the difference results from the different cross sections. The density value is given in atmospheres as a convenient unit. In order to obtain the density in units of $\mathrm{m}^{-3}$, one has to multiply the values by the Loschmidt number $\mathrm{L}=2.69 * 10^{25} \mathrm{~m}^{-3}$.

The density traces are marked at three levels by circles, one at the foot of the pulse front one at the middle of the pulse front and one at the top of the pulse front. The levels are found semi-automatically by fitting the pulse rise by a linear function and by calculating the intersections with the origin, with the given maximum and with the half value of the maximum. This data is discussed in figures 17 and 18.

Figs. 14 to 16 give the amplitudes for the gases $\mathrm{He}$, Ne and argon for both guiding tubes. Data are shown as far as they can be analyzed. The curves are linear which is consistent with our earlier statement that the pulse shape is preserved for a given gas and a given position. In all cases the amplitude in the $38 \mathrm{~mm}$ tube is about a factor of 10 higher than the one in the 102 $\mathrm{mm}$ tube, in agreement with the finding in the previous figure. This factor is somewhat higher than expected from the ratio of the tube cross sections which amounts to 7.2. The higher factor would be consistent with a higher flow velocity in the bigger tube. One also sees the clear trend that the amplitudes decrease systematically from the entrance window via the middle window to the end window because the gas pulse is smeared out. In addition one finds 
that the amplitudes for Ar are the highest, for Ne are in the middle and for He are the lowest, i.e. they are ordered in the sequence of their sound velocity.

Figure 17 displays the time when the pulse arrives at the different positions. The characteristic times are the foot, the middle and the top as marked by circles in figure 13. The data represent averages of all filling pressures of the valve. The arrival time is ordered according to the sound speed of the different gases and does not depend on the tube diameter within the experimental uncertainty.

The velocities for the three amplitude levels are calculated from the time difference between the measurement position at the beginning and at the end of tube (figure 18). Within the error margin, the velocities do not vary for the two tubes. In agreement with the data of the previous publication the progression of the foot occurs with Mach speed $M_{0}$ of about 2.5, while $M_{0}$ is close to one for the maximum. Here the Mach number is related to the initial sound speed at room temperature.

The most interesting quantity is the gas flow, which is not directly measured, but can be estimated from the following considerations. We construct a waveform for the velocity by taking the measured velocities for the three amplitude levels defined above for the non stationary phase of the gas flow. In the following quasi-stationary phase, we define an effective velocity such that the integrated flow equals the total amount of injected gas. These velocities are given in figure 19a for the three measurement positions. The dashed lines are the datapoints for the $102 \mathrm{~mm}$ tube and the solid lines are those for the $38 \mathrm{~mm}$ tube. Because of the expansion in the $102 \mathrm{~mm}$ tube, the velocities achieved in the quasi-stationary phase are significantly higher than for the $38 \mathrm{~mm}$ tube. The maximum achievable velocity in the stationary phase $v_{\max }=f\left(A_{\text {orifice }} / A_{\text {tube }}\right)\left(2 c_{p} T\right)^{1 / 2}$ is indicated for He, Ne and Ar at room temperature. Here, the different tube diameter give $f\left(A_{\text {orifice}} / A_{\text {tube }}\right)=0.88(102 \mathrm{~mm})$ and 0.7 (38mm). For the $102 \mathrm{~mm}$ tube the achieved velocities are close to $\mathrm{v}_{\max }$, whereas in the $38 \mathrm{~mm}$ tube other processes like for example friction might be considered to explain the low velocities. Modelling of the gas flow dynamics would be needed here for more insight. With the data from the density measurement in the tube and the pressure measurement in the Pitot device, the velocity can be derived in the quasi-stationary phase. An example for Argon injection is given in figure 20. A good agreement of the estimated velocities with the constructed velocities in the quasi-stationary phase is found. The velocities obtained from the effective speed and the Pitot data are summarized in Table 1. 
By integration of the flow, we get the normalised number of injected particles

$\tilde{N}(t)=\frac{\int_{0}^{t} \rho\left(t^{\prime}\right) \cdot v\left(t^{\prime}\right) \cdot A_{\text {tube }} d t^{\prime}}{Q}$,

which is given in figure 19b. Here $\rho$ is the density, $v$ the velocity, $A_{\text {tube }}$ the cross section of the tube, and $Q$ the total amount of gas stored in the valve. Because of the disturbance at the first measurement position in the $38 \mathrm{~mm}$ tube, a reliable estimate of the flow is not possible at this position. The 102mm tube shows a faster gas delivery at the middle of the tube after about $40 \%$ of the gas has past this point. However, at the last measurement position, about $4 \mathrm{~m}$ away from the valve exit, both tubes show a similar behaviour within the error bar. Additionally, we can compare the measurements to an estimate of the number of injected particles for an adiabatic gas expansion:

$$
\tilde{N}(t)=1-\exp \left(-\frac{c_{s}}{V}\left(\frac{2}{\kappa+1}\right)^{1 / \kappa-1} \int_{0}^{t} A\left(t^{\prime}\right) d t^{\prime}\right),
$$

with $\mathrm{V}$ being the volume of the valve, $\mathrm{k}$ is the adiabatic index and $c_{s}$ being the sound speed, which is reached at the orifice of the nozzle with temporal varying area $A(t)$. This area is taken from the measurements of the piston motion and is kept constant when $\mathrm{A}=\pi^{*} \mathrm{r}^{2}$ is reached. This estimate indicates the limit for the gas delivery in stationary approximation, it can only be overcome if non-stationary dynamics are taken into account. The dotted lines in figure 21 give the gas delivery from this estimate in comparison to the measured number of injected particles for $\mathrm{L}=185 \mathrm{~m}$ in the $102 \mathrm{~mm}$ tube. The measured gas delivery is quite close to this stationary limit.

The time available to inject the gas into the plasma is determined by the duration of the cooling phase. This phase starts when the first gas arrives in the plasma edge and lasts until the thermal quench. After the thermal quench the fuelling efficiency drops significantly. The duration of the cooling phase depends on the plasma parameters as well as on the injected species [22]. Figure 22 shows the time delay from the time when the first gas arrives until $50 \%$ has passed the three positions in the tube. This delivery time increases with the mass of the injected species and is shortest for helium. However, with respect to disruption mitigation, one purpose of the gas injection is to reduce the heat loads by radiation. Thus, one has to take into account that helium has a much lower radiation efficiency than argon or neon. In view of suppression of runaway electrons, the total number of injected electrons is the figure of merit. 
The normalised number of injected atoms $\tilde{\mathrm{N}}$ times the charge number $\mathrm{Z}$ is given in figure 19c. Because of its high charge number, argon delivers more electrons than neon and helium do in the same time.

\section{Summary and Outlook}

A new disruption mitigation valve, the DMV-30, has been developed and tested. The valve has the advantages of the previous developments: it is robust and reproducible, starts to open within one millisecond and is fully open after about 3ms. The valve operates with an eddy current drive and is not sensitive to external static magnetic fields. As compared to its predecessors it has a larger volume and opening orifice and the coil is now isolated from the gas volume by a metal casing. According to an estimate of the field penetration through the casing, the performance is not affected by the casing. The gas released by the valve is transferred through a guiding tube of $4 \mathrm{~m}$ length to a $300 \mathrm{l}$ vessel. We are using two different guiding tubes, one with an inner diameter of $38 \mathrm{~mm}$ as used presently at JET and one with $102 \mathrm{~mm}$ inner diameter.

The gas flow in the guiding tubes is measured with a new, commercial interferometer and a Pitot tube. The front of the gas pulse propagates with a Mach of about 2.5 through the tubes, independent of the two diameters. This high speed agrees with theoretical expectations for a non-stationary gas expansion into vacuum where a front speed of Mach three is predicted [42] and as it was observed in our previous experiment as well. In the quasi-stationary phase, a velocity close to sound speed has been found for the $102 \mathrm{~mm}$ tube. In the $38 \mathrm{~mm}$ tube we observe a flow velocity of only half of the sound speed.

An important quantity for estimating the effect of a possible mitigation of disruptions is the arrival time of the gas pulse. After the passage of a $4 \mathrm{~m}$ long guiding tube the front arrives after about 2-5 ms depending on the gas species. After this time of flight, it takes about 10$15 \mathrm{~ms}$ to inject $50 \%$ of the total amount of gas in the case of helium and $20-25 \mathrm{~ms}$ in the case of argon. A significant faster injection can be achieved with shorter tubes. No significant difference in gas delivery was found with respect to the tube diameter. It remains an open question, if the second density peak measured at the valve exit in the $38 \mathrm{~mm}$ tube is related to the physics of gas dynamics and if so, in how far this affects the gas delivery. This analysis is needed before a final conclusion on the optimum tube diameter can be drawn.

The optimum gas species can not be deduced from the analysis given here. It depends on the purpose of the gas injection, plasma cooling by radiation or suppression of the runaway 
avalanche by increasing the total number of electrons in the plasma. It also depends on the cooling duration, which is the time available for the gas injection. This will differ for the different species because of their different radiation efficiency.

ITER requires an injection of the order of $500 \mathrm{kPam}^{3}$ of helium or $100 \mathrm{kPam}^{3}$ of neon for the suppression of runaway electrons [41]. This is a factor 20-100 more than our present valve can inject. However, scaling to these valve sizes seems to be feasible, especially if more than one valve will be used for gas injection in ITER. For the mitigation of heat loads and forces a significant lower amount of gas will be needed. The duration of the injection is estimated to be in ITER of the order of $5-10 \mathrm{~ms}$, which has to be confirmed by a size scaling on the basis of present MGI experiments. Such a comparison between different devices requires information about the amount of gas injected until the thermal quench. This data is now at hand for the DMV-30 from the measurements presented in this paper and can be used to validate models of the gas flow. Such an analysis is in preparation and will be presented elsewhere.

\section{Acknowledgement}

This work is supported by the German Federal Ministry of Education and Research under contract number 03FUS0007. The views and opinions expressed herein are those of the authors alone.

\section{References}

${ }^{1}$ ITER Physics Basis Editors 1999 Nucl. Fusion 39, p. 2137

2 ITER Physics Expert Group on Disruptions, Plasma Control and MHD 1999, Nucl. Fusion 39, p. 2251

${ }^{3}$ ITER Physics Expert Group on Disruptions, Plasma Control and MHD 1999, Nucl. Fusion 39, p. 2577

${ }^{4}$ Progress in the ITER Physics Basis: MHD stability, operational limits and disruptions, Nucl. Fusion 47 (2007) S128-S202

${ }^{5}$ K.H. Finken, W.Y. Baek, K.H. Dippel, A.J. Russo, J.G. Watkins, J.A. Boedo, D.S. Gray, "Energy Flux to the TEXTOR Limiters during Disruptions", Nucl. Fus., 32 (1992) 915

${ }^{6}$ R. Jaspers, T. Grewe, K.H. Finken, A. Krämer-Flecken, N.J. Lopes Cardozo, G. Mank, G, Waidmann, "Observations of Infrared Radiation during Disruptions in TEXTOR: Heat Pulses and Runaway Electrons", J. Nucl. Mater., 220-222 (1995) 682

${ }^{7}$ K.H. Finken, T. Denner, G. Mank, “Thermal load distribution on the ALT-II limiter of TEXTOR-94 during RI mode, operation and during disruptions”, Nucl. Fusion, 40 (2000) 339

${ }^{8}$ K.H. Finken, A. Kraemer-Flecken, G. Mank, S.S. Abdullaev, "Thermal load distribution on the ALT-II limiter of TEXTOR-94 during disruptions”, J. Nucl. Mater., 290-293 (2001) 1064

${ }^{9}$ V Riccardo, P Andrew, L C Ingesson and G Maddaluno“Disruption heat loads on the JET MkIIGB divertor” Plasma Phys. Control. Fusion 44, (2002) 905-929 
${ }^{10}$ S.A. Bozhenkov, M. Lehnen, K.H. Finken, M.W. Jakubowski, R.C. Wolf, R. Jaspers, O.V. Marchuk, E. Uzgel, G. Van Wassenhove, O. Zimmermann, D. Reiter and the TEXTOR team, "Generation and suppression of runaway electrons in disruption mitigation experiments in TEXTOR”, Plasma Phys. Control. Fusion 50 (2008) 105007

${ }^{11}$ R. Jaspers, N.J. Lopes Cardozo, K.H. Finken, T. Grewe, G. Mank, F.C. Schüller, "Disruption Generated Runaway Electrons in TEXTOR and ITER", Nucl. Fusion, 36 (1996) 367

${ }^{12}$ K.H. Finken, A. Kraemer-Flecken, M. Lehnen, A. Savtchkov, ”Disruptions - a proposal for their mitigation by runaway suppression“, J. Nucl. Mater., 313-316 (2003) 1247

${ }^{13}$ K.H. Finken, G. Mank, A. Krämer-Flecken, R. Jaspers, „Mitigation of Disruptions by fast helium gas puffs“, Nucl. Fusion, 41 (2001) 1651

${ }^{14}$ K. H. Finken, R. Jaspers, A. Krämer-Flecken, A. Savtchkov, M. Lehnen, G. Waidmann, ”Disruptions and Their Mitigation in TEXTOR”, Fusion Science and Technology, 47 (2005), 266-273

${ }^{15}$ D. G. Whyte, T. C. Jernigan, D. A. Humphreys, A. W. Hyatt, C. J. Lasnier, P. B. Parks, T. E. Evans, M. N. Rosenbluth, P. L. Taylor, A. G. Kellman, D. S. Gray, E. M. Hollmann, and S. K. Combs,

"Mitigation of Tokamak Disruptions Using High-Pressure Gas Injection”

Phys. Rev. Lett., 89, (2002) 055001

16 E.M. Hollmann, T.C. Jernigan, M. Groth, D.G. Whyte, D.S. Gray, M.E. Austin, B.D. Bray, D.P. Brennan, N.H. Brooks, T.E. Evans, D.A. Humphreys, C.J. Lasnier, R.A. Moyer, A.G. McLean, P.B. Parks, V. Rozhansky, D.L. Rudakov, E.J. Strait and W.P. West, "Measurements of impurity and heat dynamics during noble gas jetinitiated fast plasma shutdown for disruption mitigation in DIII-D”, Nucl. Fusion 45 (2005) 1046-1055

${ }^{17}$ M. Bakhtiari, H. Tamai, Y. Kawano, G.J. Kramer, A. Isayama, T. Nakano, Y. Kamiya, R. Yoshino, Y. Miura, Y. Kusama and Y. Nishida "Study of plasma termination using high-Z noble gas puffing in the JT60U tokamak” Nucl. Fusion 45 (2005) 318-325

${ }^{18}$ R. Granetz, D.G. Whyte, V.A. Izzo, T. Biewer, M.L. Reinke, J. Terry, A. Bader, M. Bakhtiari, T. Jernigan and G. Wurden "Gas jet disruption mitigation studies on Alcator C-Mod” Nucl. Fusion 46, (2006) 1001-1008

${ }^{19}$ R.S. Granetz et al., Nucl. Fusion 47 (2007) 1086-1091

${ }^{20}$ E. Hollmann et al., Nucl. Fusion 48 (2008) 115007

${ }^{21}$ G. Pautasso et al., Plasma Phys. Control. Fusion 51 (2009) 124056

${ }^{22}$ M. Lehnen et al., 36th EPS Conference on Plasma Phys. Sofia, June 29 - July 3, 2009 ECA Vol.33E, O-2.001 (2009)

${ }^{23}$ Jardin, S.C., Schmidt, G.L., Fredrickson, E.D. et. Al., Nucl. Fusion, 40 (2000) 923

${ }^{24}$ Rosenbluth, M.N., Putvinski, S.V., Parks, P.B., Nucl. Fusion, 37 (1997) 955

${ }^{25}$ Yoshino, R., Tokuda, S., Nucl. Fusion, 40 (2000) 1293

r

${ }^{26}$ M. Lehnen, S.A. Bozhenkov, S.S. Abdullaev and the TEXTOR Team, Phys. Rev. Lett., 100 (2008) 255003

${ }^{27}$ Wróblewski, D., Jahns, G.L., Leuer, J.A., Nucl. Fusion, 37 (1997) 725

${ }^{28}$. Pautasso, G., Egorov, S., Tichmann, Ch., Fuchs J.C., Herrmann, A., Maraschek, M., Mast, F., Mertens, V., Perchermeier, I., Windsor, C.G., and Zehetbauer, T., "Prediction and mitigation of disruptions in ASDEX Upgrade" J. Nucl. Mater., 290-293, ( 2001), 1045 
${ }^{29}$ G. Pautasso, C. Tichmann, S. Egorov"1, T. Zehetbauer, O. Gruber, M. Maraschek, K.-F. Mast, V. Mertens, I. Perchermeier, G. Raupp, W. Treutterer, C.G. Windsor ${ }^{2}$ and ASDEX Upgrade Team

"On-line prediction and mitigation of disruptions in ASDEX Upgrade"

Nucl. Fusion 42 (2002) 100-108

${ }^{30}$ Buttery, R.J., Günter, S., Giruzzi, G. et al., Plasma Physics and Contr. Fusion, 42, Suppl. 12B (2000) B61

${ }^{31}$ Kislov, D.A., Alikaev, V.V., Esipchuk Y.V., et al., Nucl. Fusion, 37 (1997) 339

${ }^{32}$ Savrukhin, V.P., Lyadina, E.S., Martynov, D.A. et al.,, Nucl. Fusion, 34 (1994) 317

${ }^{33}$ Morris, A.W., Hender, T.C., Hugill, J., et al., Phys. Rev. Lett., 64 (1990) 1254

${ }^{34}$ Raupp, G., Gruber, O., Kallenbach, A., et al., Fusion Technol., 32 (1997) 444

${ }^{35}$ A. Krämer-Flecken, K.H. Finken, V.S. Udintsev, H. Larue and the TEXTOR team, Nucl. Fusion ,43 (2003) 1437-1445

${ }^{36}$ La Haye, R.J., Rettig, C.L., Groebner R.J., Hyatt, A.W., Scoville, J.T., Phys. Plasmas, 1 (1994) 373

${ }^{37}$ La Haye, R.J., Fitzpatrick, R., Hender, T.C., Morris, A.W., Scoville, T.J., Todd, T.N., Phys. Fluids B 4 (1992) 2098

${ }^{38}$ A. Savtchkov, K.H. Finken, G. Mank, „Development of a fast valve for mitigating disruptions in tokamaks“, Review of Scientific Instruments, 73 (2002) 3490

${ }^{39}$ S. A. Bozhenkov, K.-H. Finken, M. Lehnen, and R. C. Wolf, "Main characteristics of the fast disruption mitigation valve”, Review of Scientific Instruments 78, 033503 (2007)

${ }^{40}$ K.H. Finken, M. Lehnen and S.A. Bozhenkov, “Gas flow analysis of a disruption mitigation valve (DMV)”, Nucl. Fusion 48 (2008) 115001

${ }^{41}$ M. Sugihara et al., 36th EPS Conference on Plasma Phys. Sofia, June 29 - July 3, 2009 ECA Vol.33E, P-4.165 (2009)

42 S.A. Bozhenkov, M. Lehnen, K.H. Finken, M.W. Jakubowski, O.V. Marchuk, D. Reiter, R. C. Wolf and the TEXTOR team, "Efficiency of massive gas injection for increase of plasma density in TEXTOR experiments on disruption mitigation”, 36th EPS Conference on Plasma Phys. Sofia, June 29 - July 3, 2009 ECA Vol.33E, P1.180 (2009) 


\section{Figure captions:}

Fig. 1 Setup of the disruption mitigation valve (DMV), the guiding tube and the recipient. The locations for the interferometric observations are indicated. Two blocks of concrete enhance the inertia of the guiding tube in order to reduce mechanical oscillations of the tube.

Fig. 2: Sketch of the DMV-30. As compared to the previous designs, the gas reservoir of the working gas is enhanced to $1.3 \mathrm{l}$, the opening orifice is enhanced to $28 \mathrm{~mm}$ (position B) and the valve is totally enclosed in stainless steel (part A) such that the coil is now outside of the closure valve.

Fig.3a: Time trace of the coil voltage

Fig.3b: Time trace of the coil current

Fig. 4: Measured axial movement of the piston as a function of time and pressure in the injection volume. The pressure in the closure volume is 2 bar. The closure volume is filled with argon and the injection volume with helium. The voltage is $1.7 \mathrm{kV}$.

Fig. 5: Time to full opening ( $\mathrm{h}=\mathrm{r} / 2)$ as function of the applied voltage. Argon is used in the closure volume at 2 bar and helium is the gas in the injection volume at 40 bar.

Figure 6: Set-up of the interferometer.

Figure 7: Calibration curve for Ar.

Fig 8a (top): Raw data of the interferometer which shows fringe jumps imposed during the fast ramp of the gas pulse.

Fig. 8b (bottom): Correction of fringe jumps in the front of the pulse. After the correction the density signals are well reproducible.

Fig. 9: Signals at the entrance window of the $38 \mathrm{~mm}$ tube show a characteristic dip.

Fig. 10: Entrance signal similar as in Fig 9 but with an extension of the piston by a rod. Measurement position is $10 \mathrm{~cm}$ further away from valve exit compared to figure 9 .

Fig. 11: Disturbance due to mechanical oscillation of the $300 \mathrm{l}$ volume imposed by the gas pulse and its correction. The strong oscillation is only found at the end window for the 102 mm guiding tube.

Fig. 12: Photo of the Pitot tube.

Fig. 13: Density measurement for the three valve discharges, each at the middle of the tube. Fig. 13a (top) shows data for the $38 \mathrm{~mm}$ guiding tube and Fig. 13b (bottom) for the $102 \mathrm{~mm}$ tube. The pulse of the $102 \mathrm{~mm}$ tube is substantially shorter than that in the $38 \mathrm{~mm}$ tube. The density value is given in atmospheres as a convenient unit. In order to obtain the data in $\mathrm{m}^{-3}$, one has to multiply the values by the Loschmidt number $\mathrm{L}=2.69 * 10^{25} \mathrm{~m}^{-3}$. The data marked by the circles at the foot, the middle and the peak of the gas front is used in figures 17,18.

Fig. 14: Amplitudes of He gas at different filling pressures

Fig. 14a (top): Data for the $38 \mathrm{~mm}$ tube

Fig. 14b (bottom): Data for the $102 \mathrm{~mm}$ tube 
Fig. 15: Amplitudes of Ne gas at different filling pressures

Fig. 15a (top): Data for the $38 \mathrm{~mm}$ tube

Fig. 15b (bottom): Data for the $102 \mathrm{~mm}$ tube

Fig. 16: Amplitudes of Ar gas at different filling pressures

Fig. 16a (top): Data for the $38 \mathrm{~mm}$ tube

Fig. 16b (bottom): Data for the $102 \mathrm{~mm}$ tube

Fig. 17: Time of arrival of the foot, the middle and the peak of the pulse for $\mathrm{He}, \mathrm{Ne}$ and $\mathrm{Ar}$ (B - beginning, $\mathrm{M}$ - middle, $\mathrm{E}$ - end of the tube).

Fig. 17a (top): Data for the $38 \mathrm{~mm}$ tube

Fig. 17b (bottom): Data for the $102 \mathrm{~mm}$ tube

Fig. 18: Velocities of the foot, the middle and the peak of the pulse derived from the time difference between the measurement position at the beginning and at the end of the tube.

Fig. 18a (top): Data for the $38 \mathrm{~mm}$ tube

Fig. 18b (bottom): Data for the $102 \mathrm{~mm}$ tube

Fig. 19: Helium - green, Neon - red, Argon - black, dashed lines - 102mm tube, solid lines $38 \mathrm{~mm}$ tube. a) Constructed waveforms of the gas velocity. The velocities given on the right hand side indicated the theoretically achievable velocities in an ideal configuration. b) Normalised number of injected particles. c) Normalised number of particles times the charge number. The delay $t_{0}$ until first gas detection has been subtracted from the time vector.

Fig. 20: Comparison between constructed argon velocity and measurements using a Pitot tube at $\mathrm{L}=4080 \mathrm{~mm}$.

Fig. 21: Normalised number of injected particles. The dotted lines give the estimate from adiabatic expansion. The dashed lines show the data from measurements at $\mathrm{L}=185 \mathrm{~mm}$ for the $102 \mathrm{~mm}$ tube.

Fig. 22: Time required for $50 \%$ of the gas to pass the different locations for $\mathrm{He}, \mathrm{Ne}$ and $\mathrm{Ar}$. The delay $\mathrm{t}_{0}$ until the first gas arrives has been subtracted. 


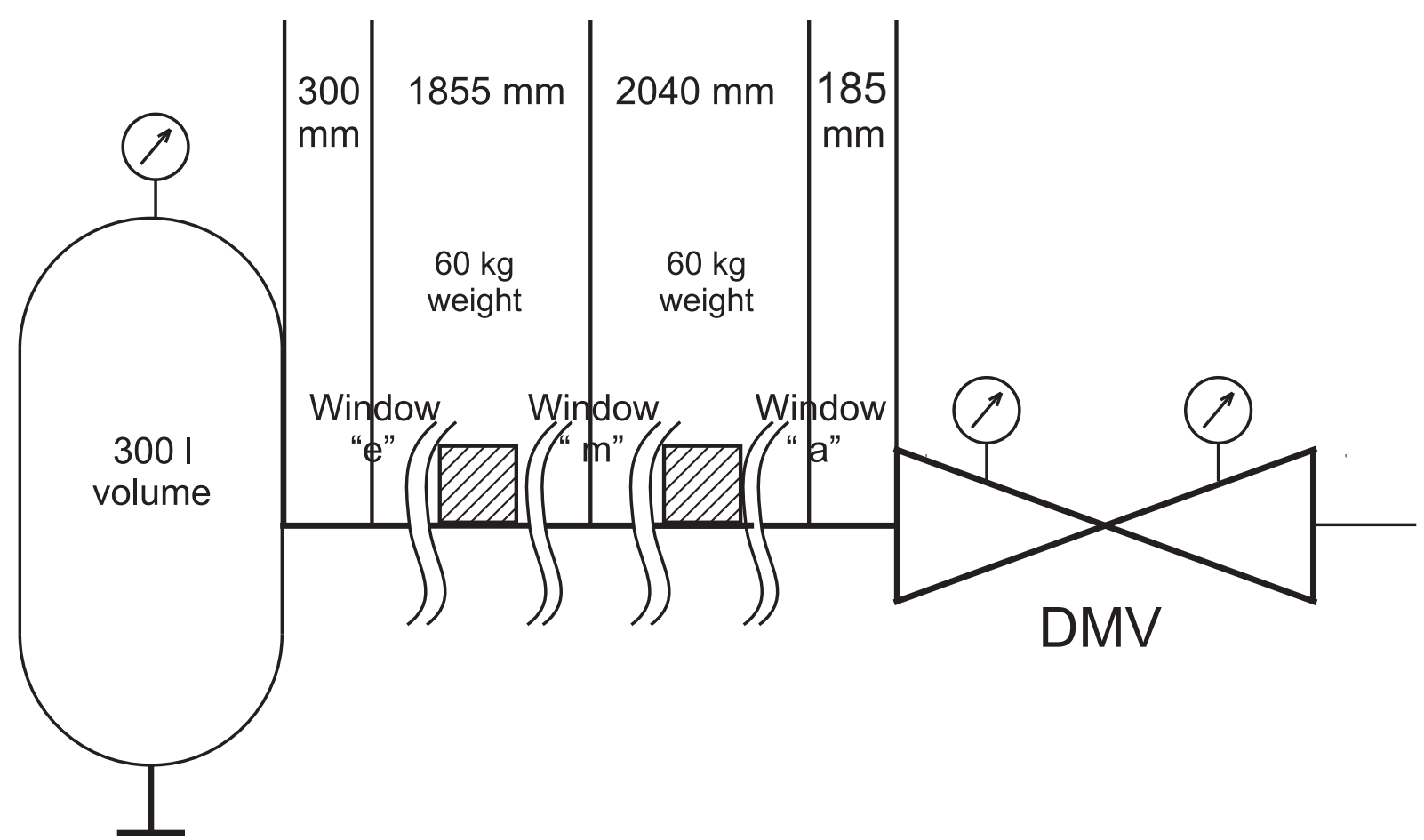

Fig. 1 Setup of the disruption mitigation valve (DMV), the guiding tube and the recipient. The locations for the interferometric observations are indicated. Two blocks of concrete enhance the inertia of the guiding tube in order to reduce mechanical oscillations of the tube.

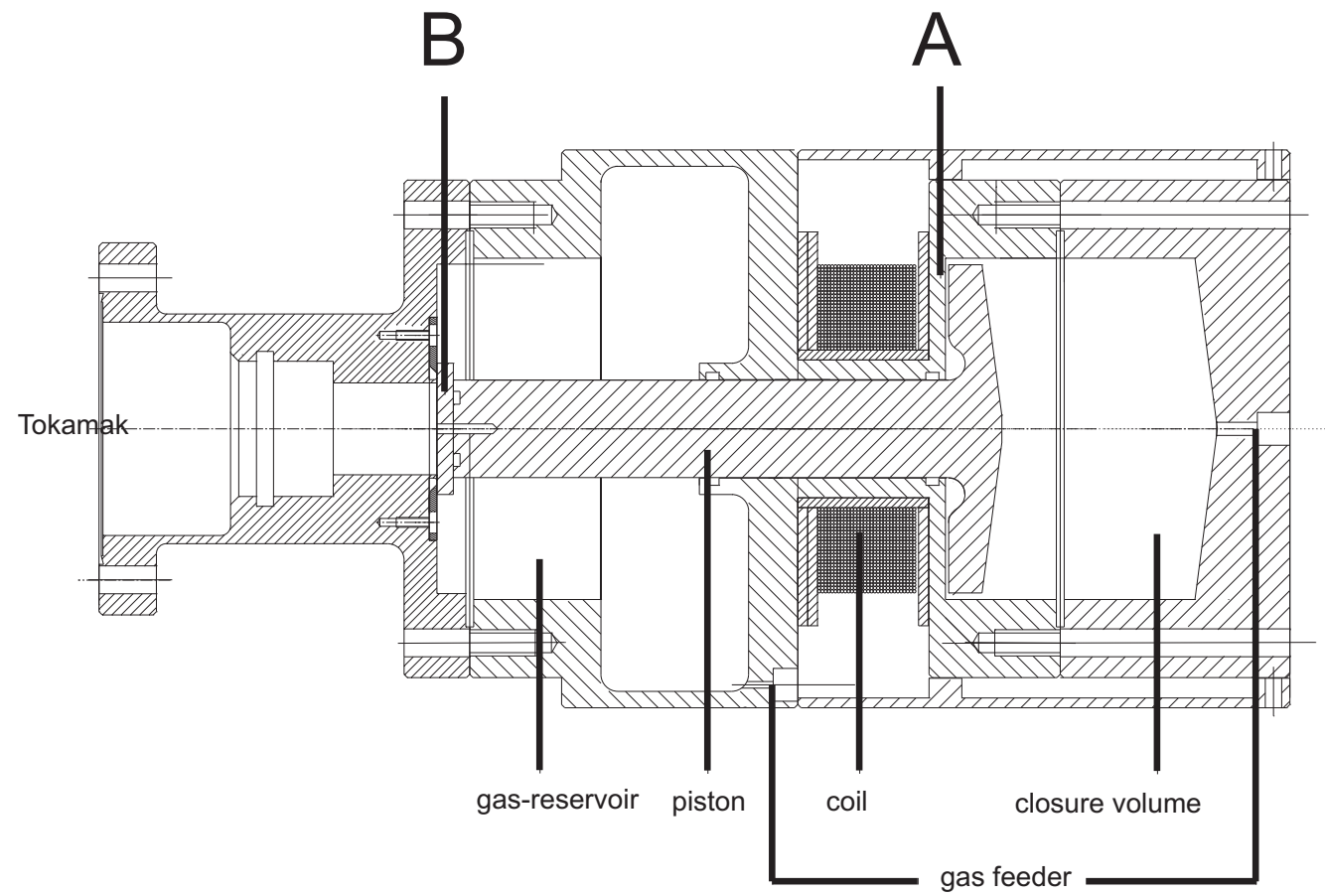

Fig. 2: Sketch of the DMV-30. As compared to the previous designs, the gas reservoir of the working gas is enhanced to $1.3 \mathrm{l}$, the opening orifice is enhanced to $28 \mathrm{~mm}$ (position $\mathrm{B}$ ) and the valve is totally enclosed in stainless steel (part A) such that the coil is now outside of the closure valve. 

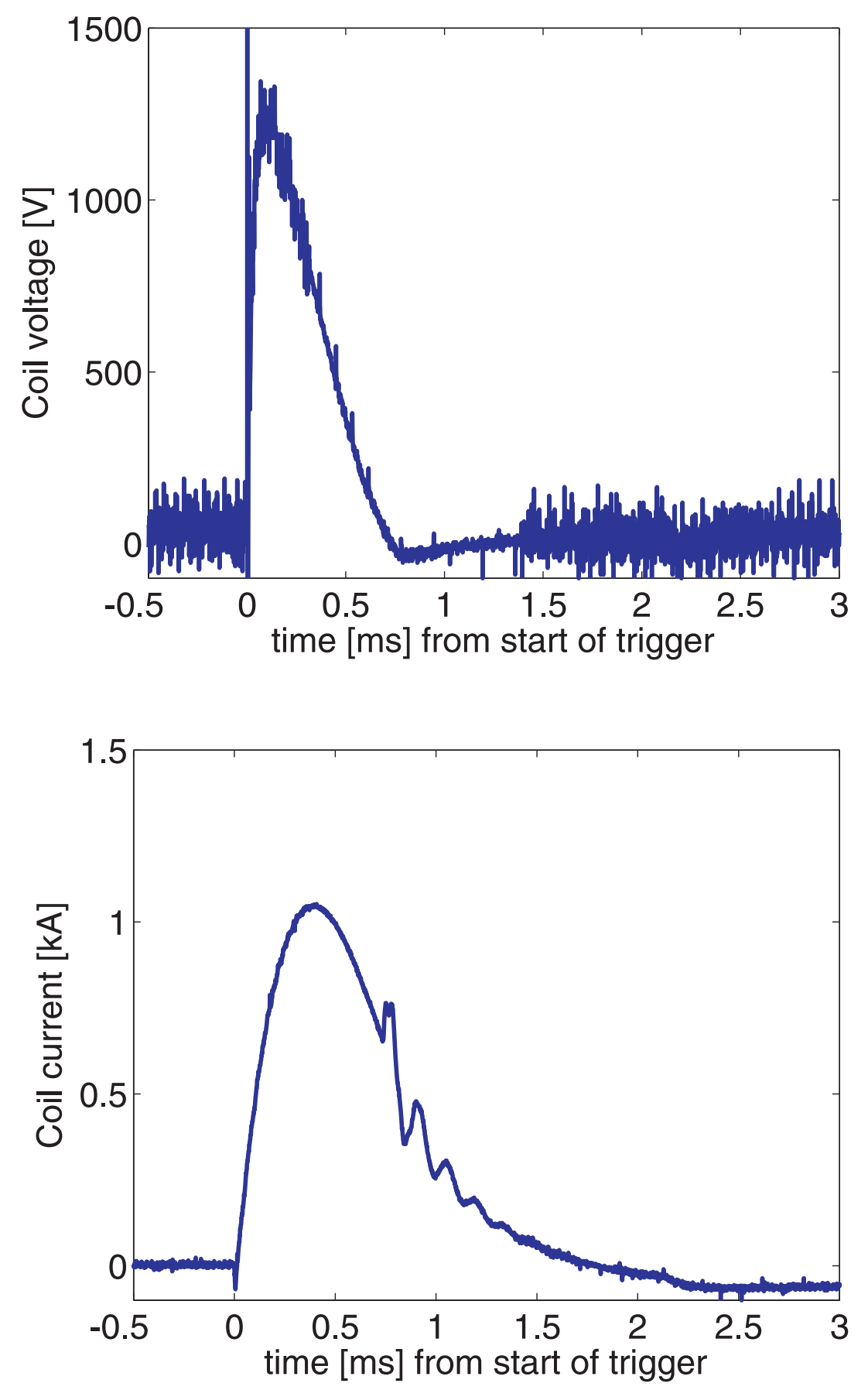

Fig.3a: Time trace of the coil voltage Fig.3b: Time trace of the coil current 


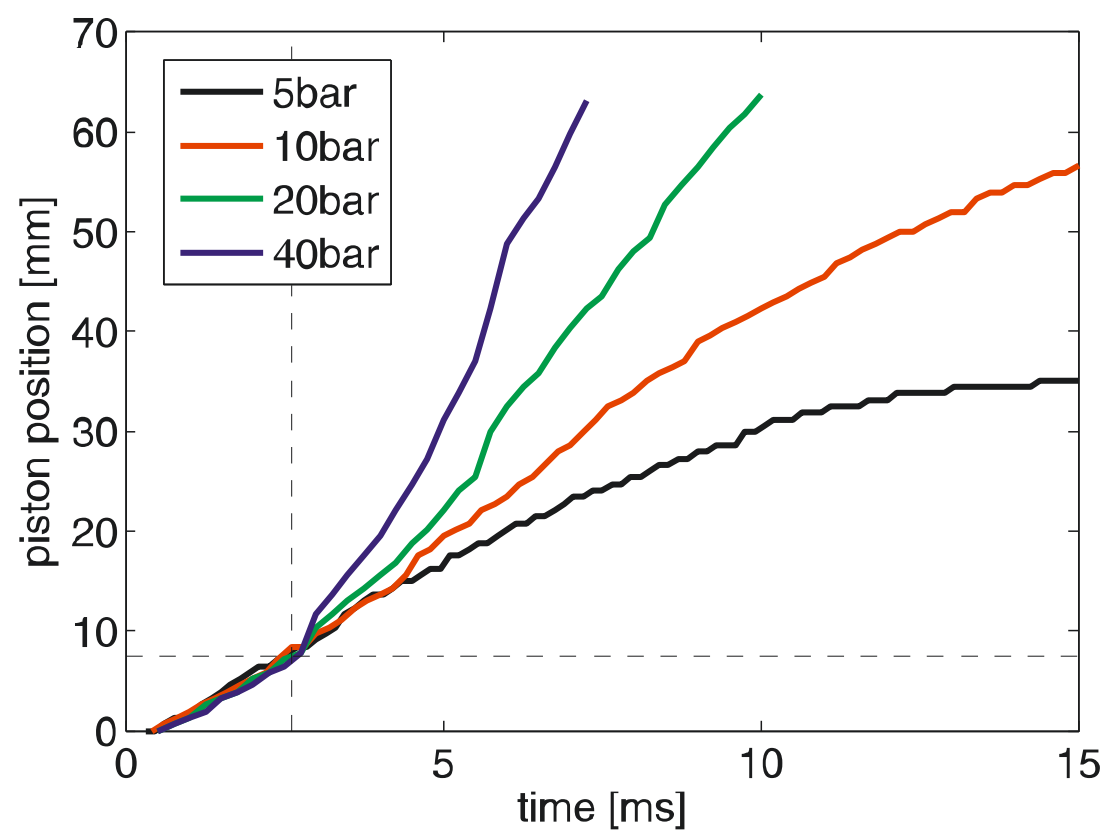

Fig. 4: Measured axial movement of the piston as a function of time and pressure in the injection volume. The pressure in the closure volume is 2 bar. The closure volume is filled with argon and the injection volume with helium. The voltage is $1.7 \mathrm{kV}$.

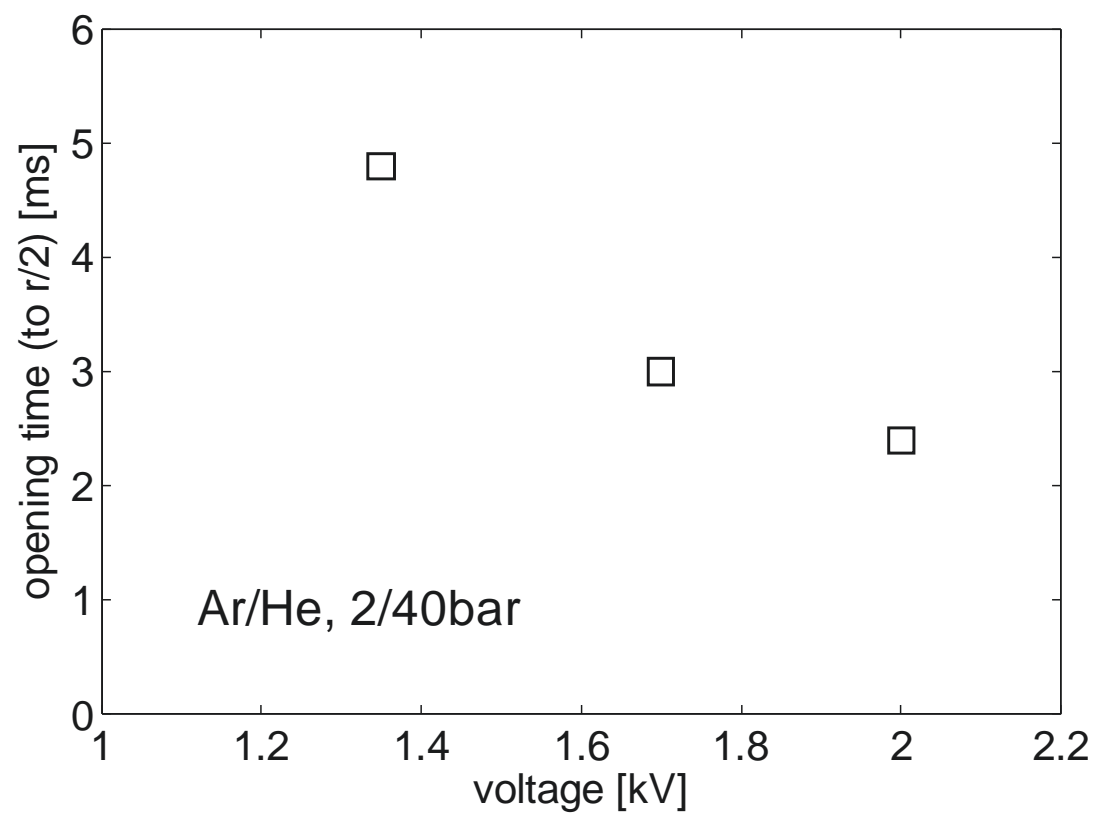

Fig. 5: Time to full opening $(\mathrm{h}=\mathrm{r} / 2)$ as function of the applied voltage. Argon is used in the closure volume at 2 bar and helium is the gas in the injection volume at 40 bar. 


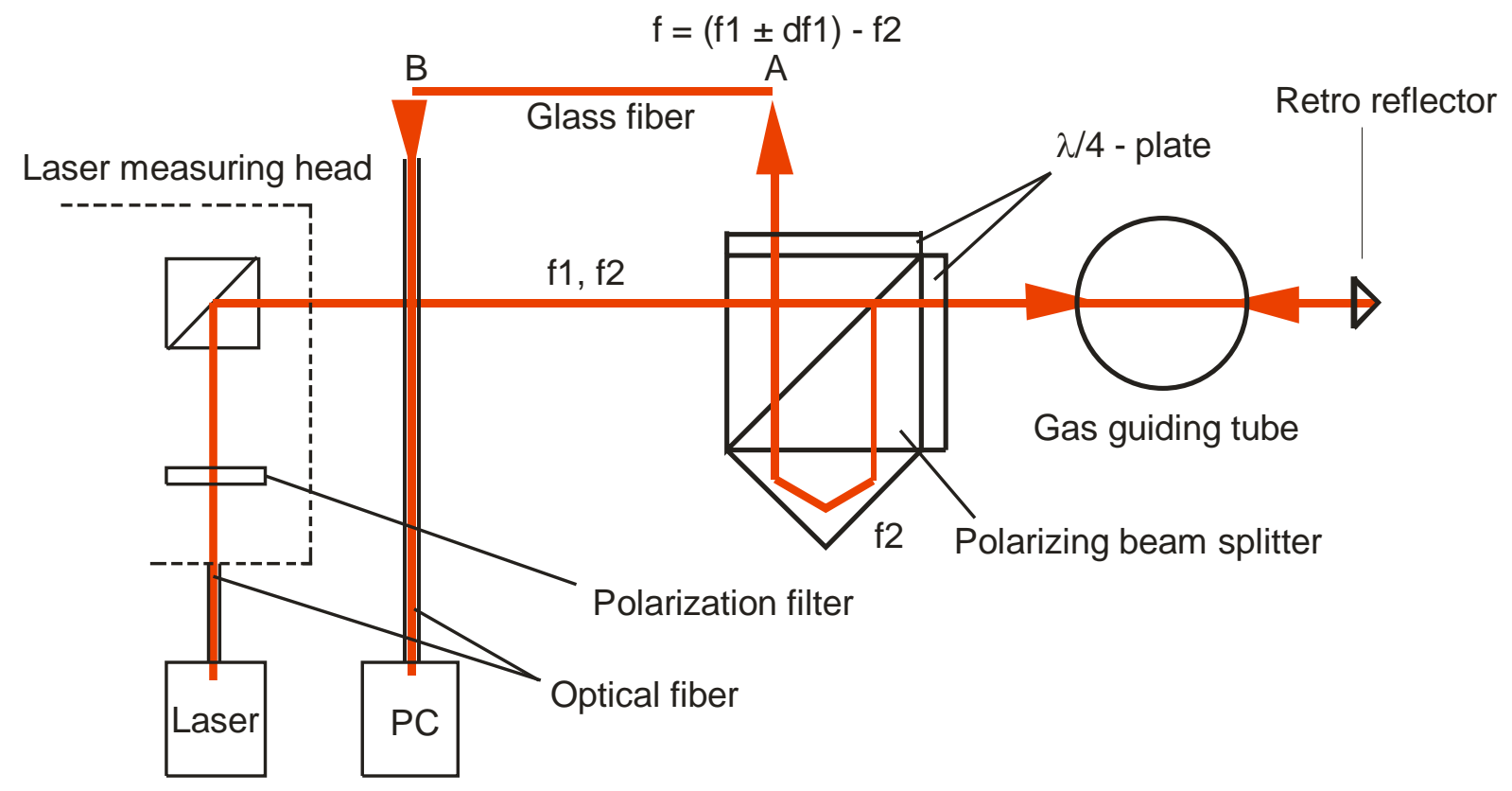

Figure 6: Set-up of the interferometer. 


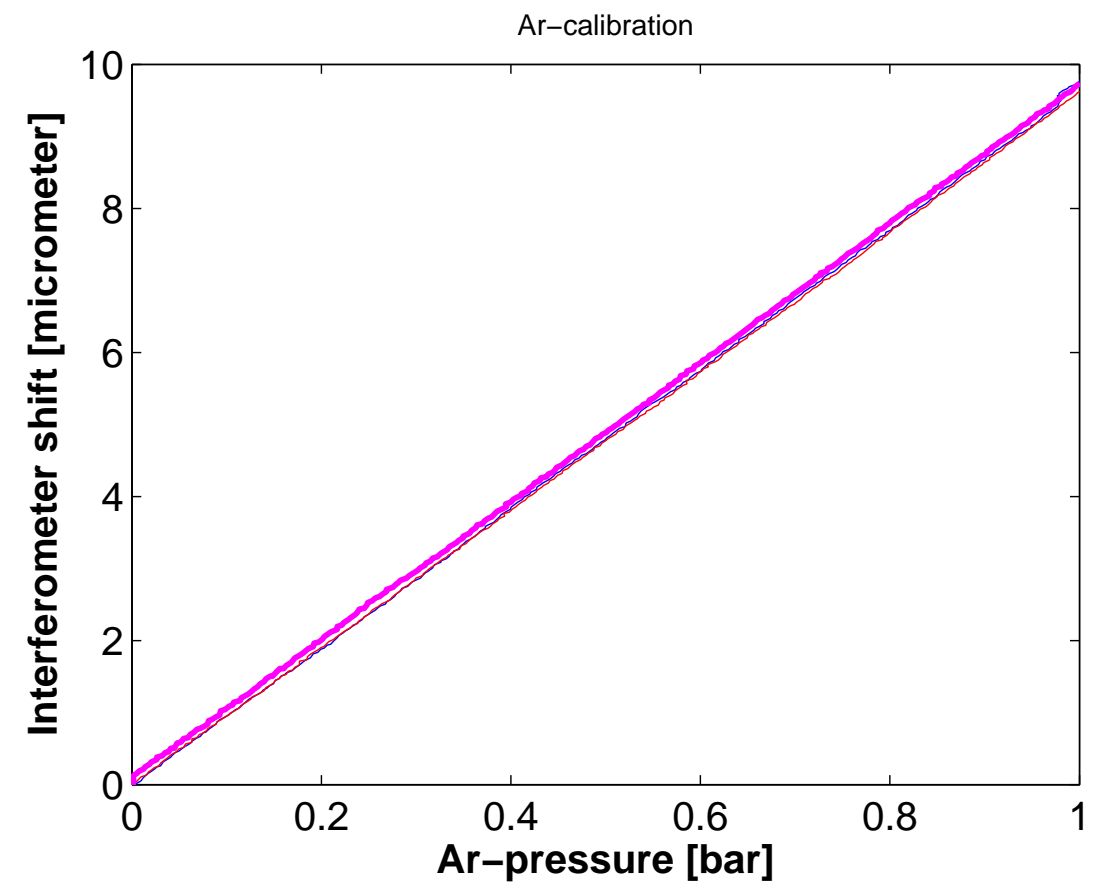

Figure 7: Calibration curve for Ar. 

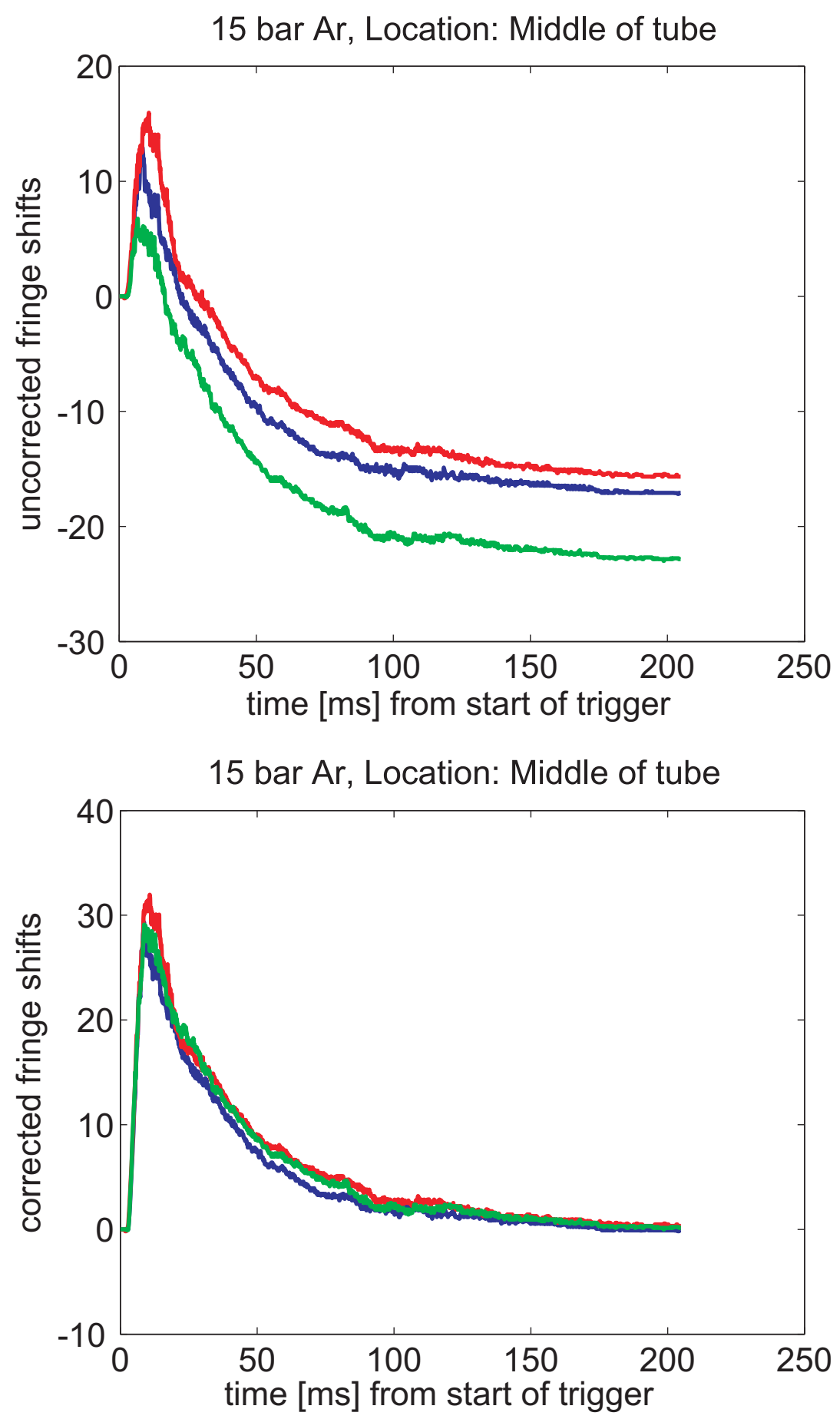

Fig 8a (top): Raw data of the interferometer which shows fringe jumps imposed during the fast ramp of the gas pulse.

Fig. 8b (bottom): Correction of fringe jumps in the front of the pulse. After the correction the density signals are well reproducible. 


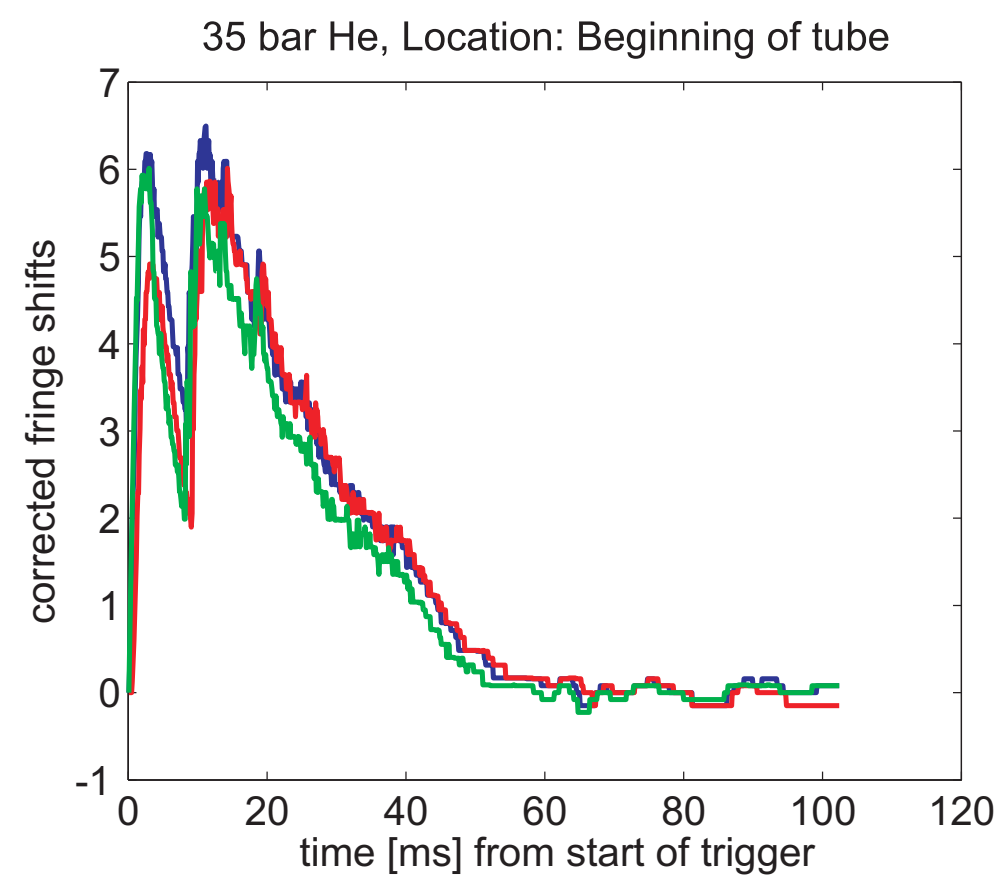

Fig. 9: Signals at the entrance window of the $38 \mathrm{~mm}$ tube show a characteristic dip.

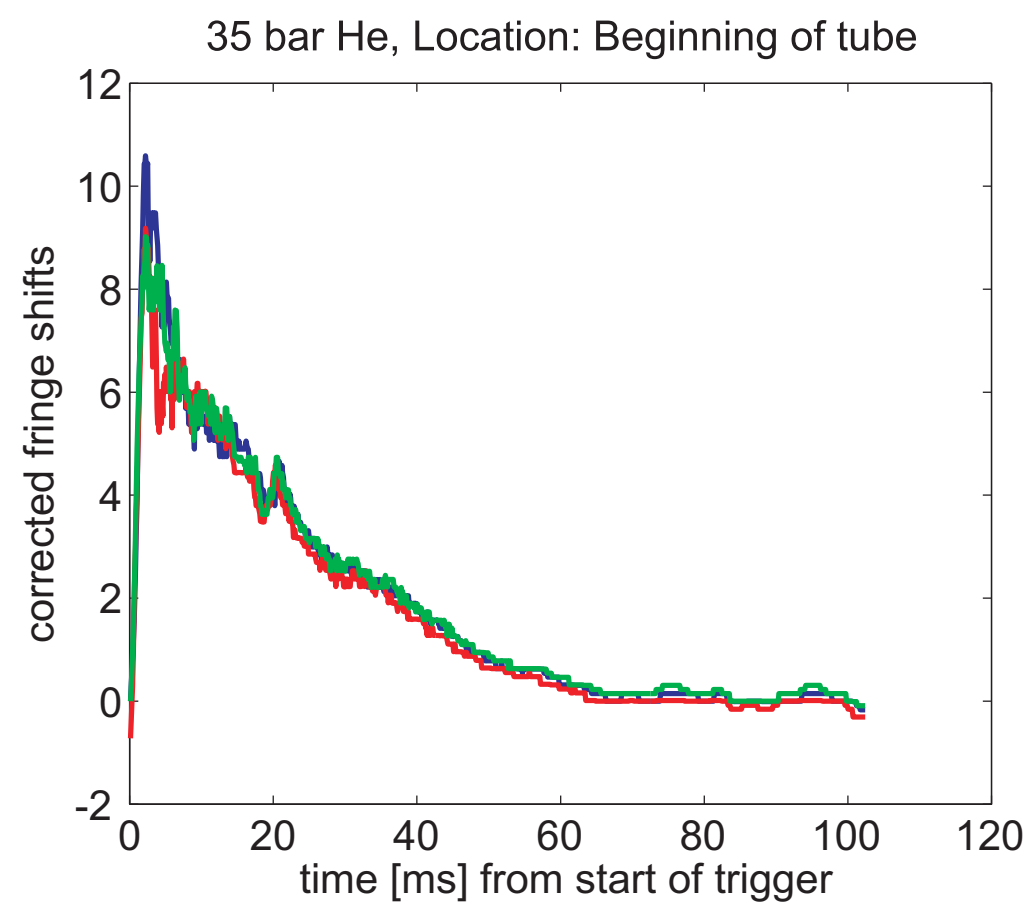

Fig. 10: Entrance signal similar as in Fig 9 but with an extension of the piston by a rod. Measurement position is $10 \mathrm{~cm}$ further away from valve exit compared to figure 9 . 


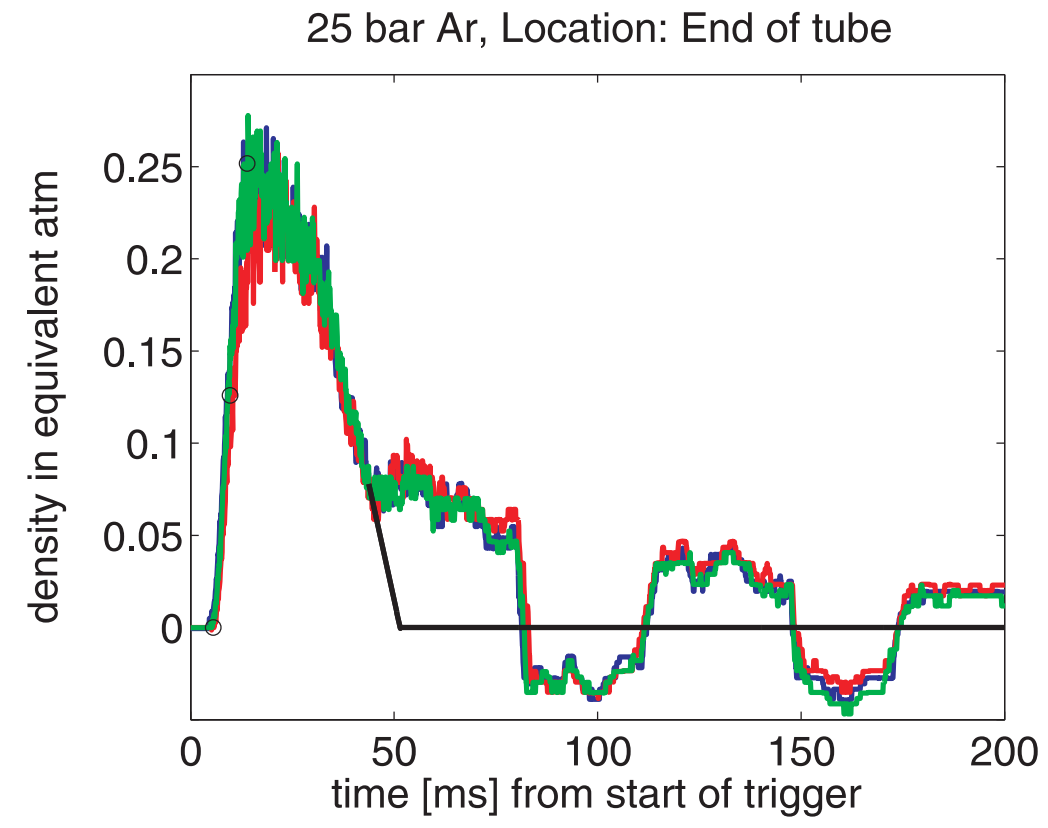

Fig. 11: Disturbance due to mechanical oscillation of the $300 \mathrm{l}$ volume imposed by the gas pulse and its correction. The strong oscillation is only found at the end window for the 102 mm guiding tube.

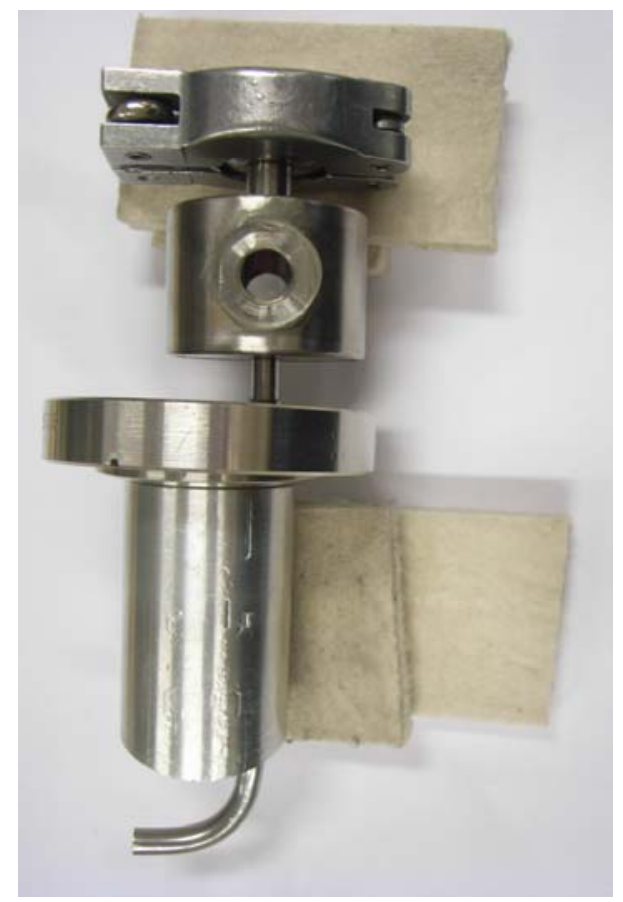

Fig. 12: Photo of the Pitot tube. 

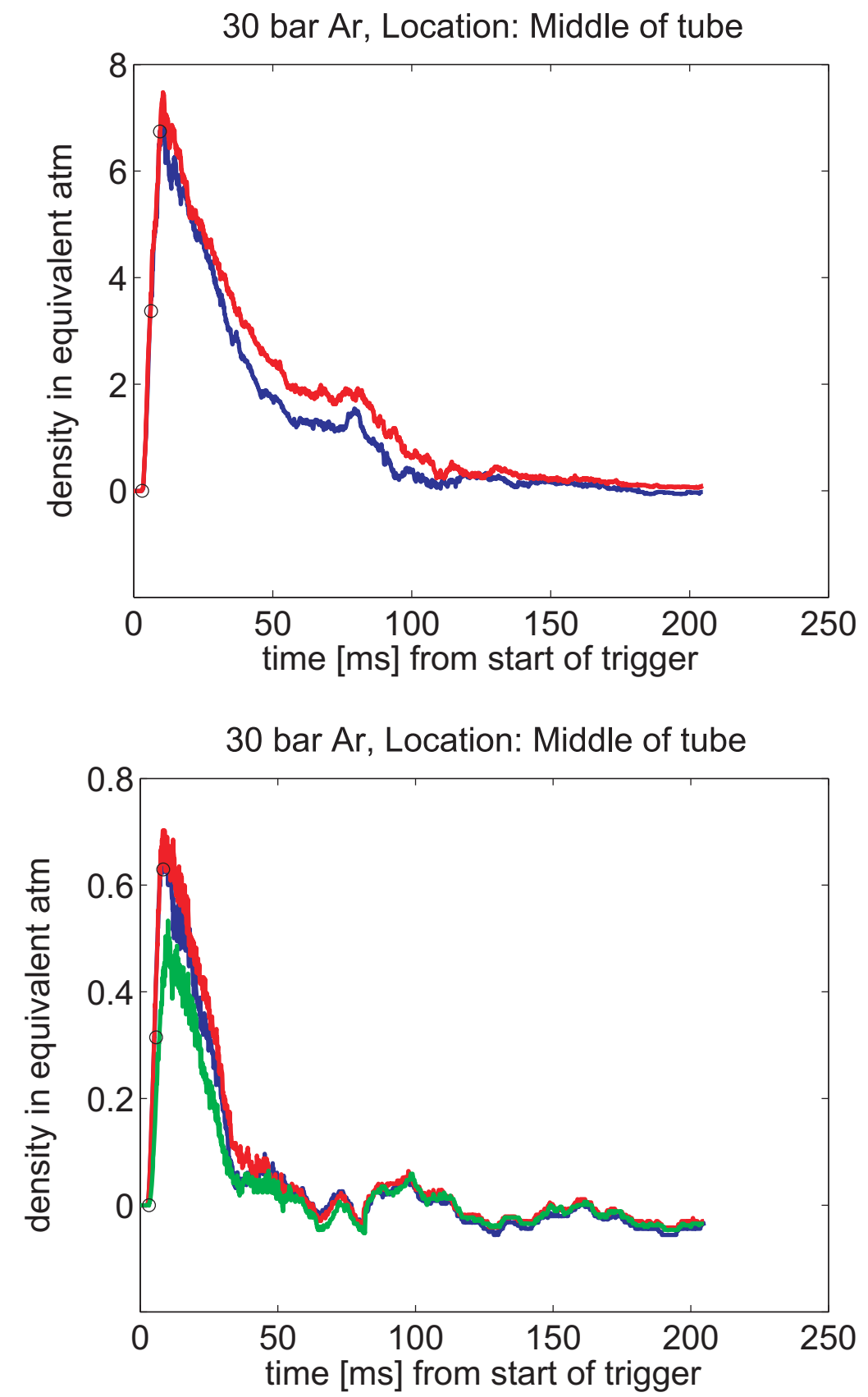

Fig. 13: Density measurement for the three valve discharges, each at the middle of the tube. Fig. 13a (top) shows data for the $38 \mathrm{~mm}$ guiding tube and Fig. 13b (bottom) for the $102 \mathrm{~mm}$ tube. The pulse of the $102 \mathrm{~mm}$ tube is substantially shorter than that in the $38 \mathrm{~mm}$ tube. The density value is given in atmospheres as a convenient unit. In order to obtain the data in $\mathrm{m}^{-3}$, one has to multiply the values by the Loschmidt number $\mathrm{L}=2.69 * 10^{25} \mathrm{~m}^{-3}$. The data marked by the circles at the foot, the middle and the peak of the gas front is used in figures 17,18. 
He-amplitude, $38 \mathrm{~mm}$ i.d. tube

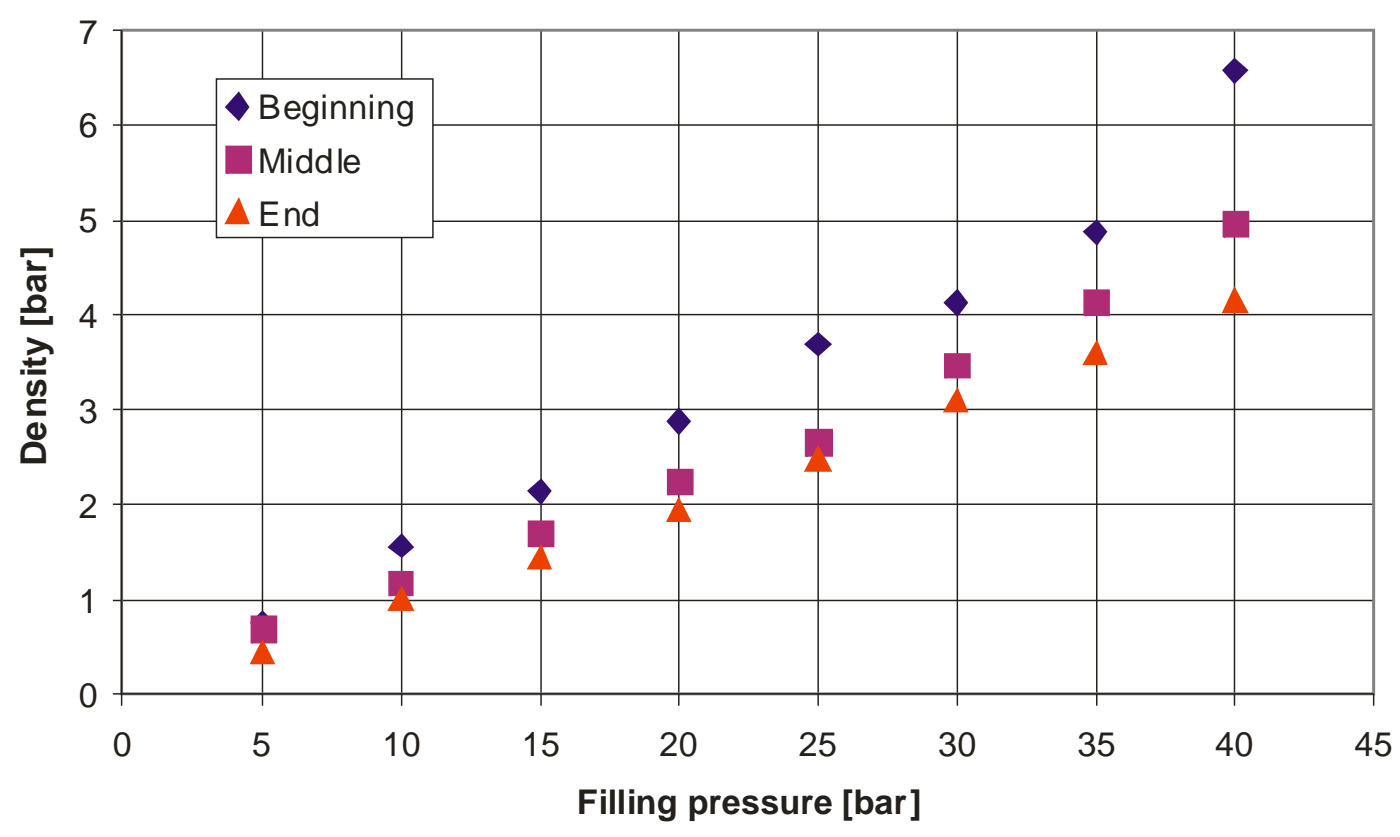

He-amplitude, 102 mm i.d. tube

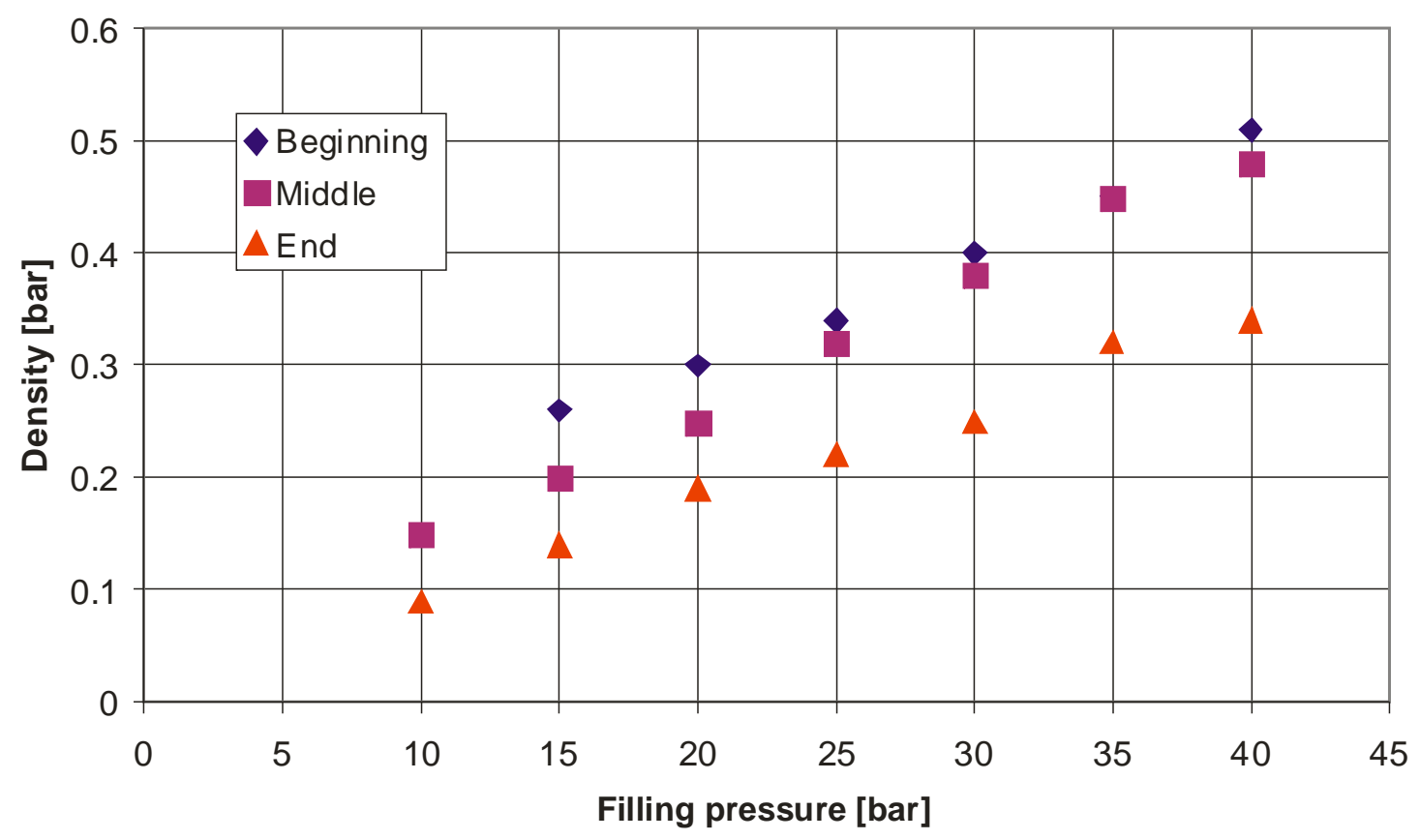

Fig. 14: Amplitudes of He gas at different filling pressures

Fig. 14a (top): Data for the $38 \mathrm{~mm}$ tube

Fig. 14b (bottom): Data for the $102 \mathrm{~mm}$ tube 
Ne-amplitude, $38 \mathrm{~mm}$ i.d. tube

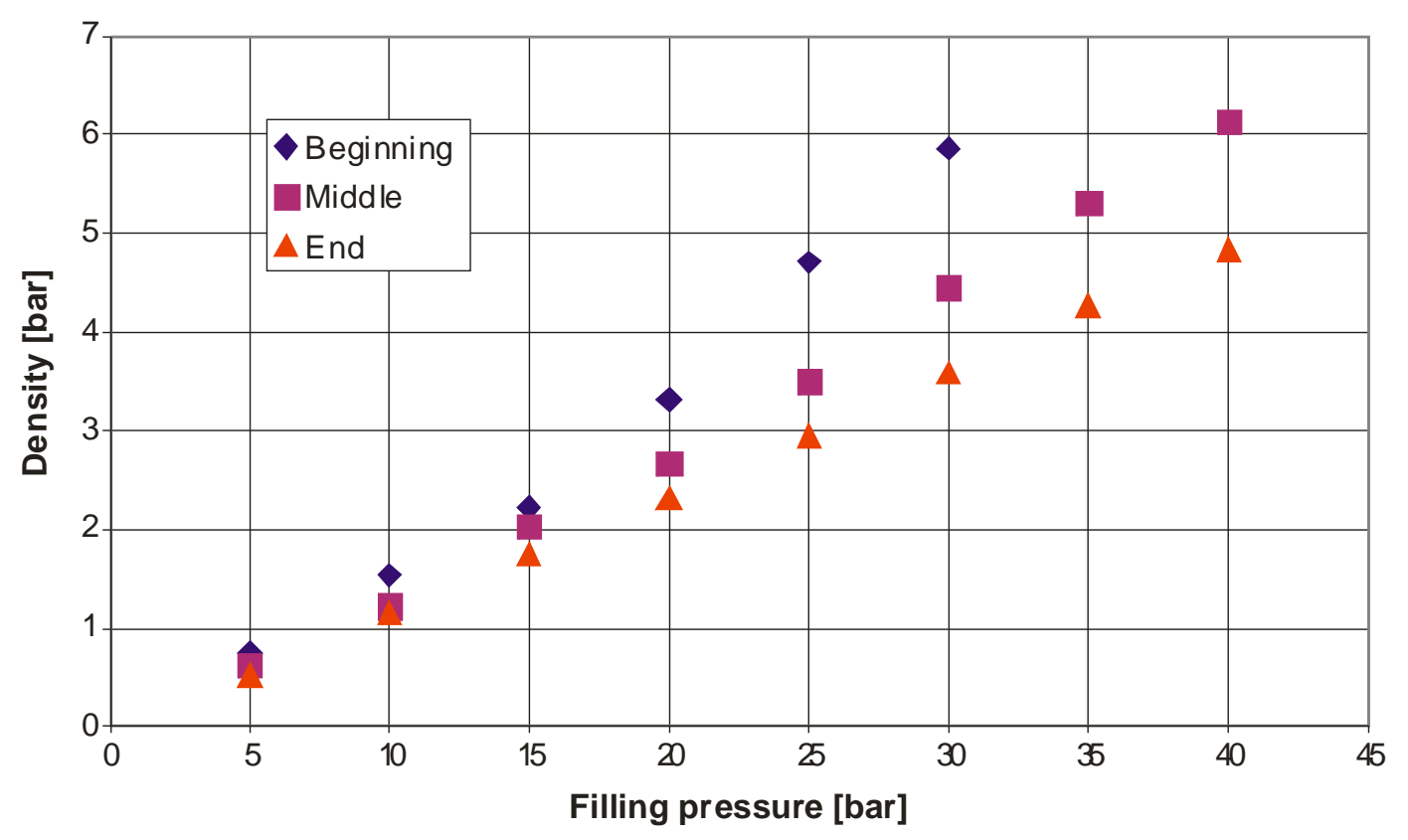

Ne-amplitude, 102 mm i.d. tube

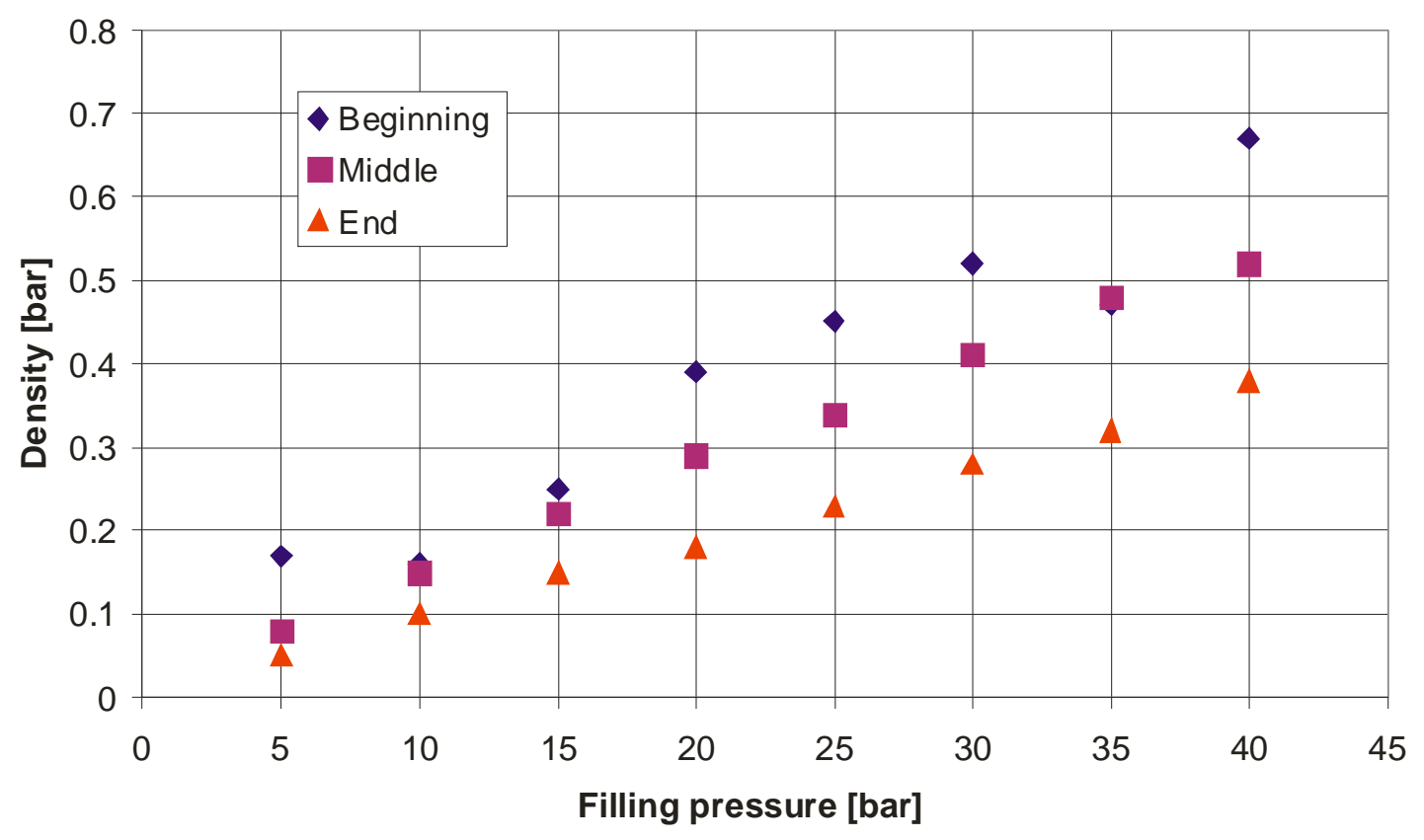

Fig. 15: Amplitudes of Ne gas at different filling pressures

Fig. 15a (top): Data for the $38 \mathrm{~mm}$ tube

Fig. 15b (bottom): Data for the $102 \mathrm{~mm}$ tube 
Ar-amplitude, $38 \mathrm{~mm}$ i.d. tube

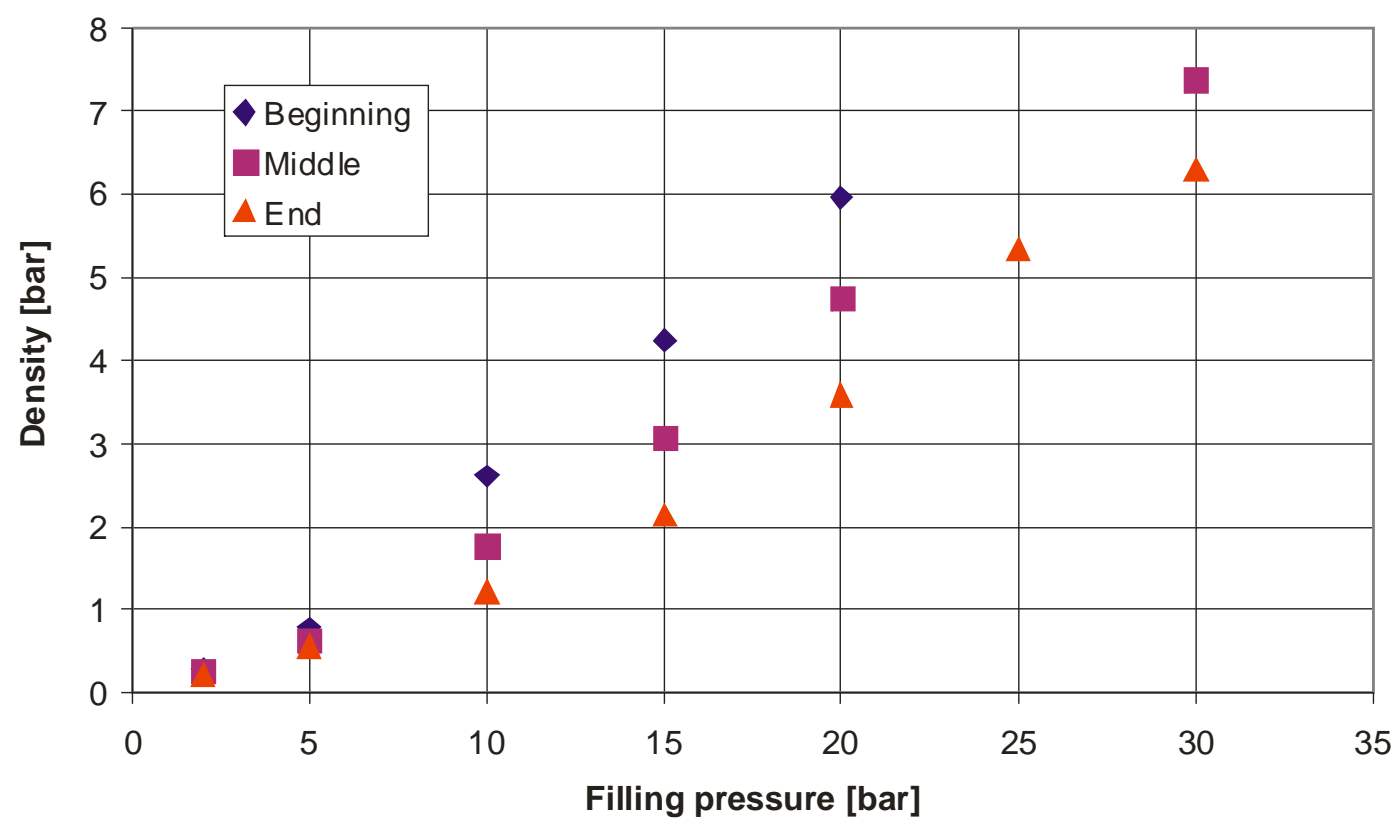

Ar amplitude, 102 mm i.d. tube

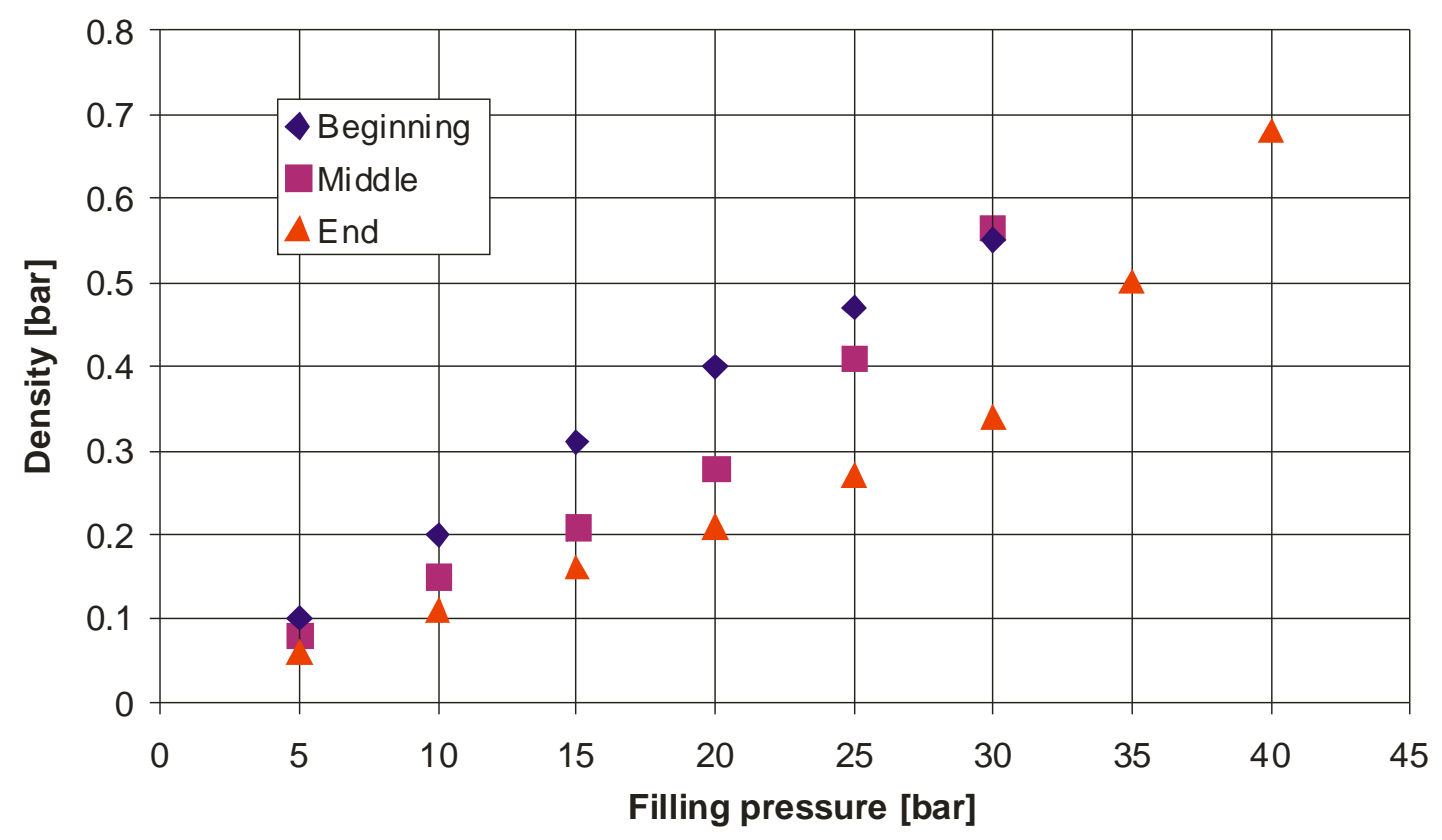

Fig. 16: Amplitudes of Ar gas at different filling pressures

Fig. 16a (top): Data for the $38 \mathrm{~mm}$ tube

Fig. 16b (bottom): Data for the $102 \mathrm{~mm}$ tube 


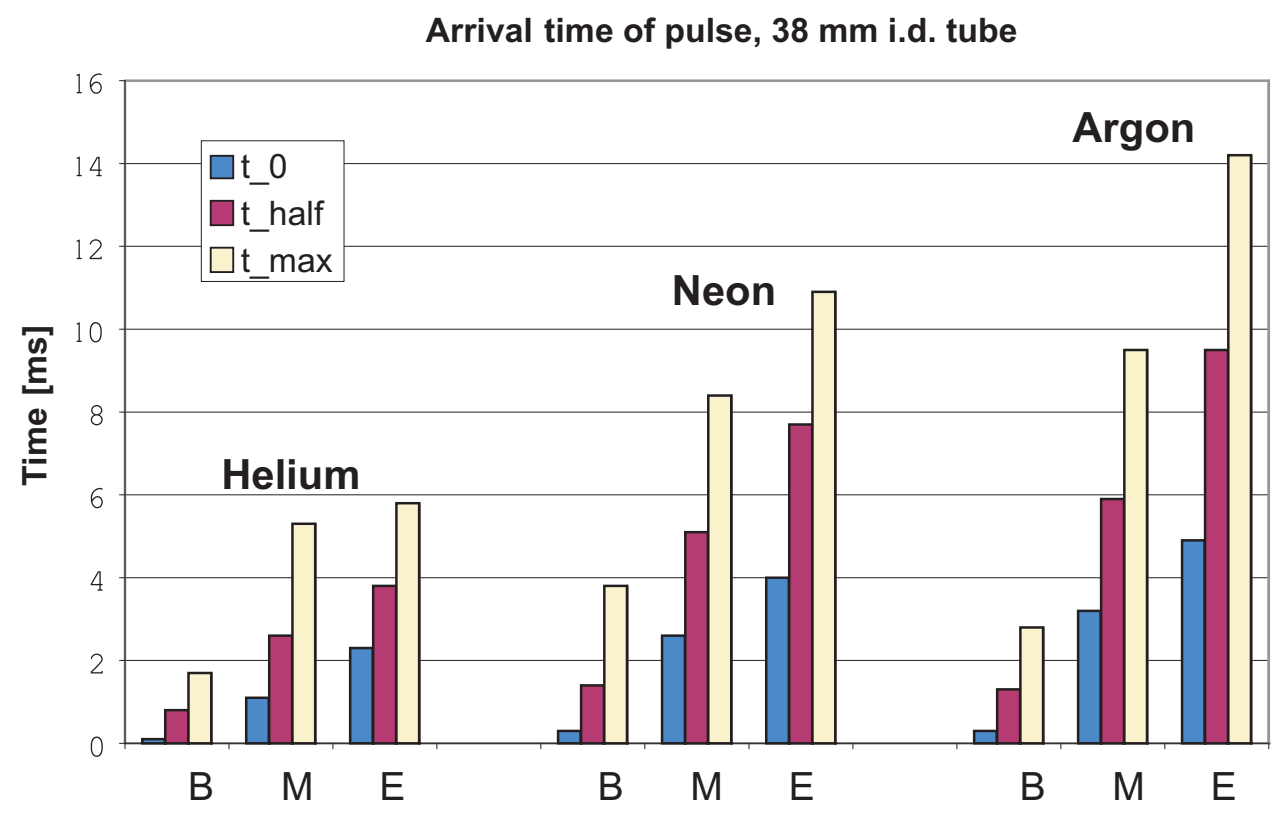

Arrival time of pulse, $102 \mathrm{~mm}$ tube

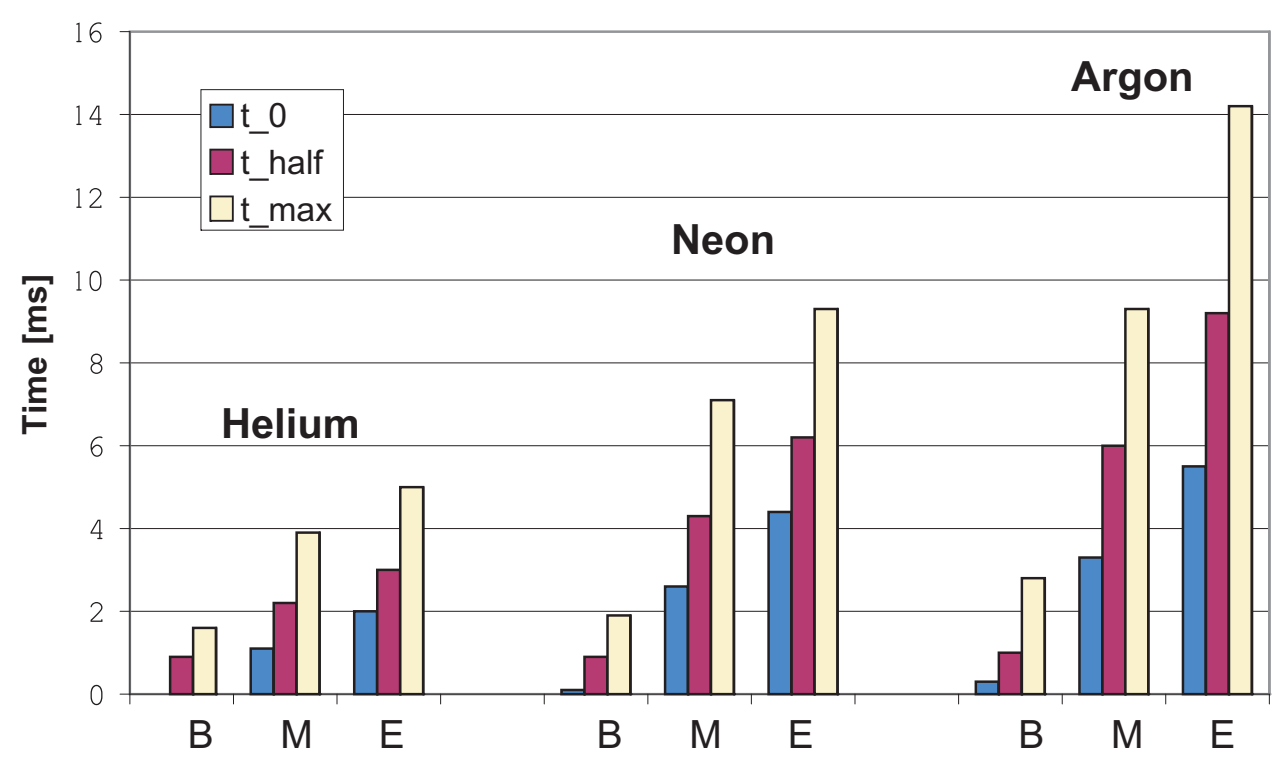

Fig. 17: Time of arrival of the foot, the middle and the peak of the pulse for He, Ne and $\mathrm{Ar}(\mathrm{B}$ - beginning, $\mathrm{M}$ - middle, $\mathrm{E}$ - end of the tube).

Fig. 17a (top): Data for the $38 \mathrm{~mm}$ tube

Fig. 17b (bottom): Data for the $102 \mathrm{~mm}$ tube 
Front velocity, $38 \mathrm{~mm}$ i.d. tube

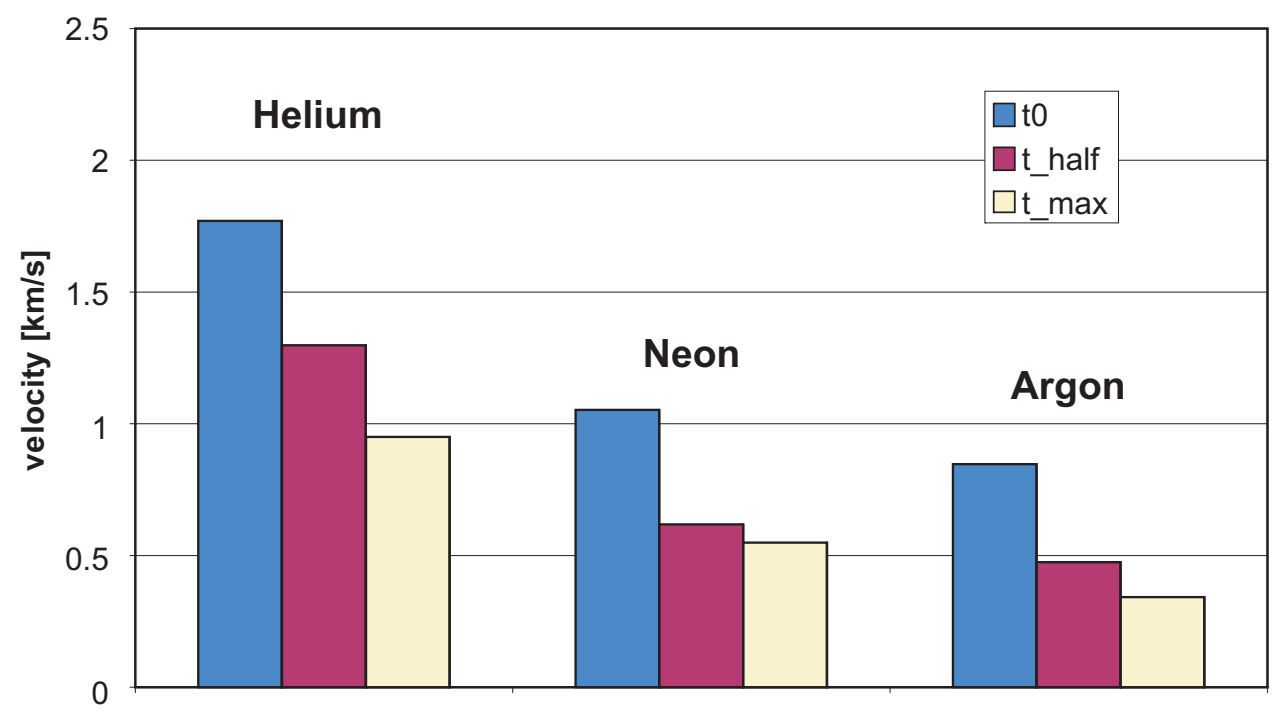

Front velocity, $102 \mathrm{~mm}$ i.d. tub

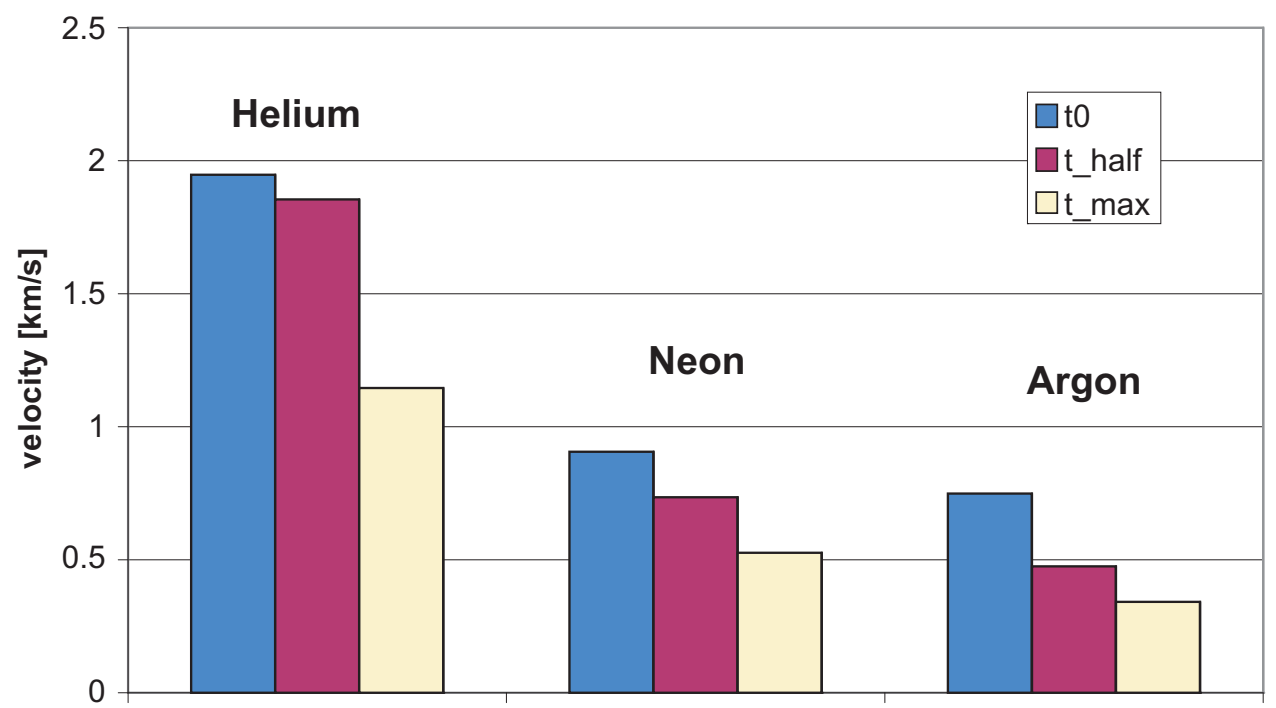

Fig. 18: Velocities of the foot, the middle and the peak of the pulse derived from the time difference between the measurement position at the beginning and at the end of the tube. Fig. 18a (top): Data for the $38 \mathrm{~mm}$ tube

Fig. 18b (bottom): Data for the $102 \mathrm{~mm}$ tube 

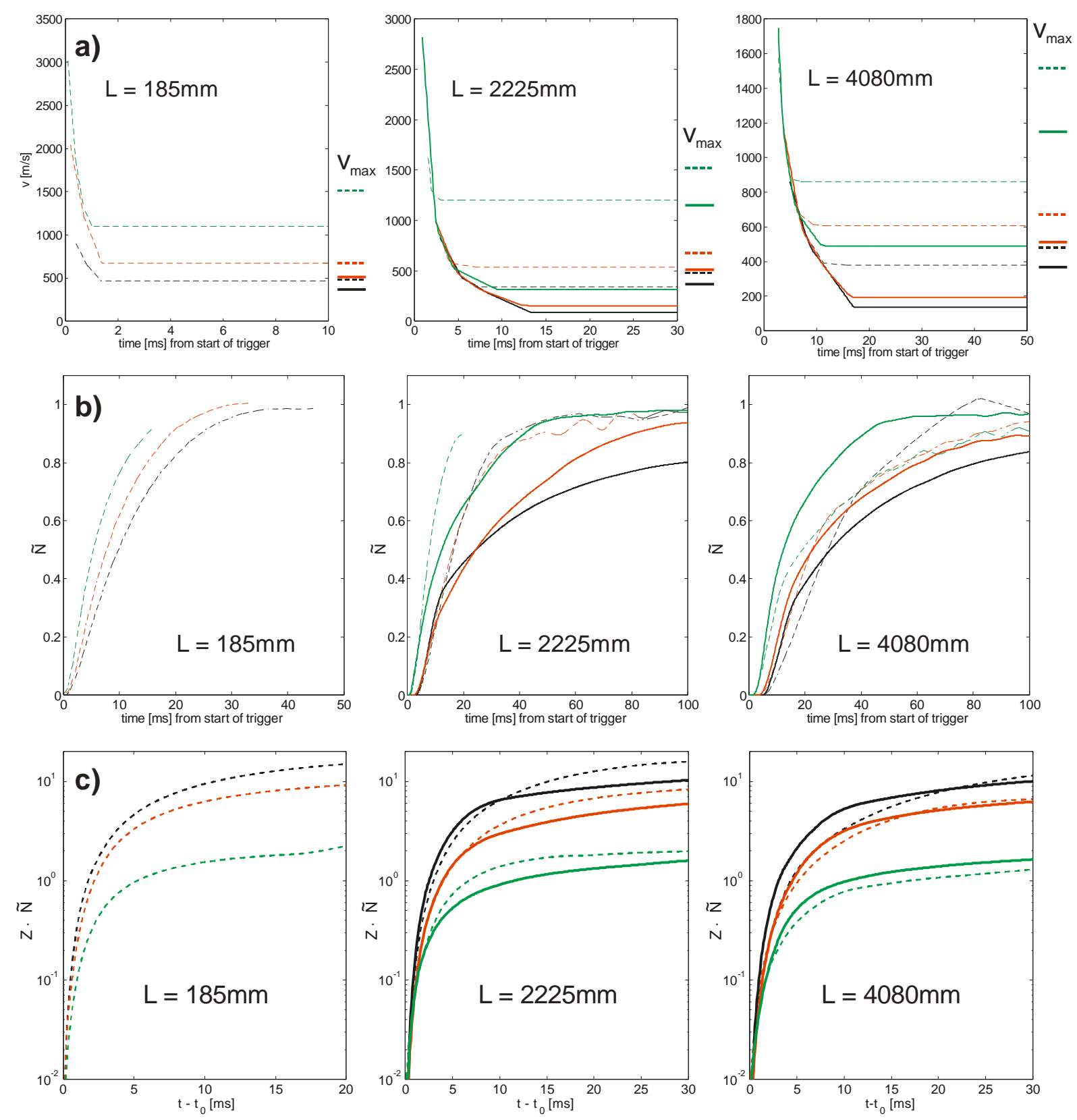

Fig. 19: Helium - green, Neon - red, Argon - black, dashed lines - 102mm tube, solid lines $38 \mathrm{~mm}$ tube. a) Constructed waveforms of the gas velocity. The velocities given on the right hand side indicated the theoretically achievable velocities in an ideal configuration. b) Normalised number of injected particles. c) Normalised number of particles times the charge number. The delay $\mathrm{t}_{0}$ until first gas detection has been subtracted from the time vector. 


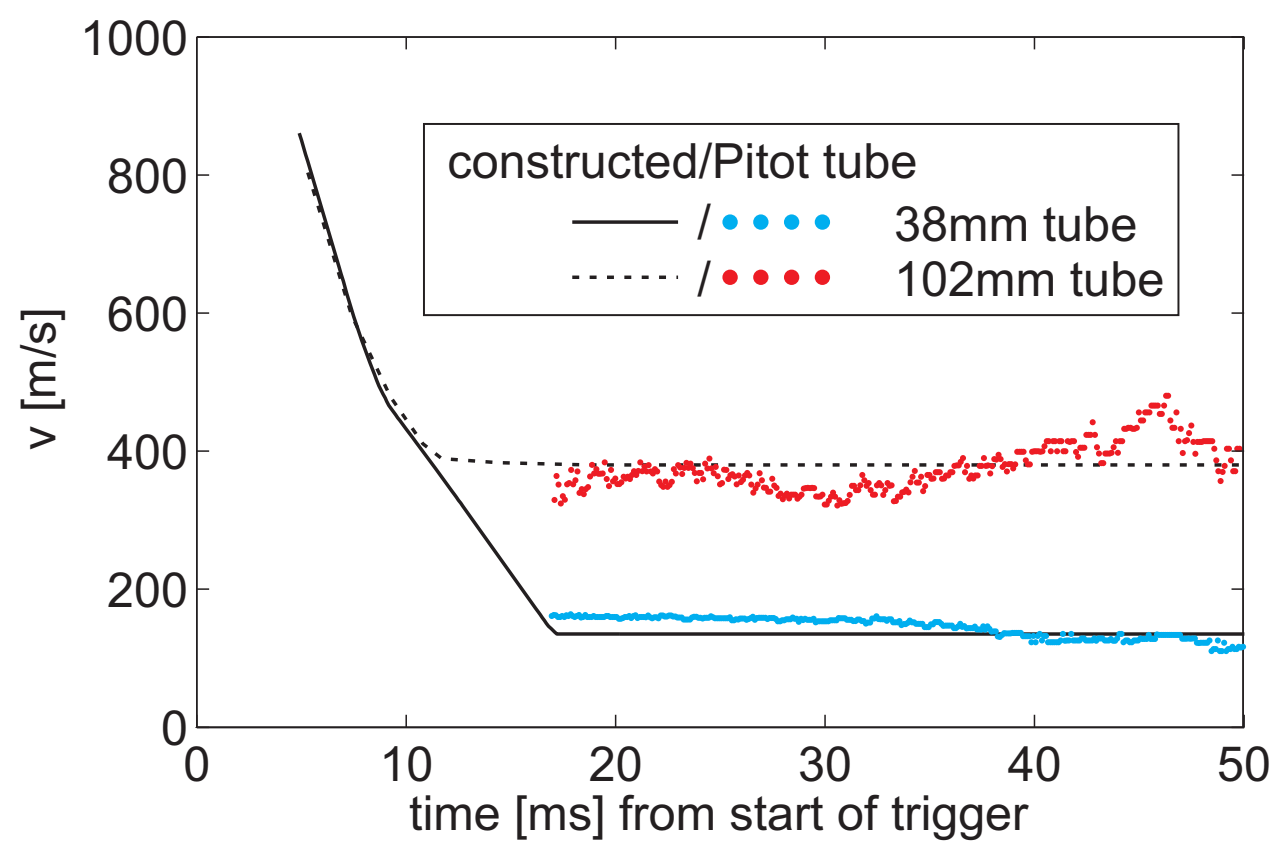

Fig. 20: Comparison between constructed argon velocity and measurements using a Pitot tube at $\mathrm{L}=4080 \mathrm{~mm}$.

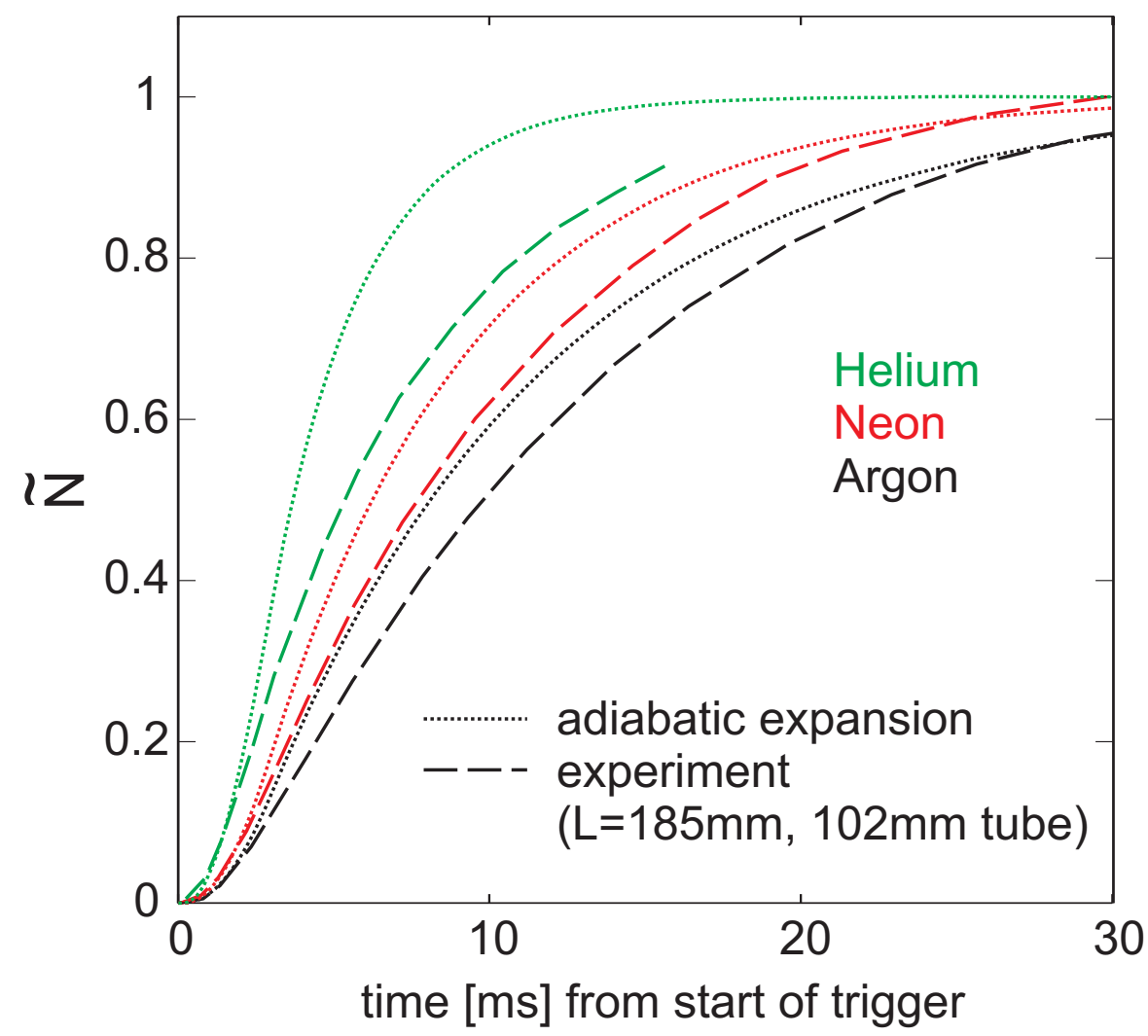

Fig. 21: Normalised number of injected particles. The dotted lines give the estimate from adiabatic expansion. The dashed lines show the data from measurements at $\mathrm{L}=185 \mathrm{~mm}$ for the $102 \mathrm{~mm}$ tube. 


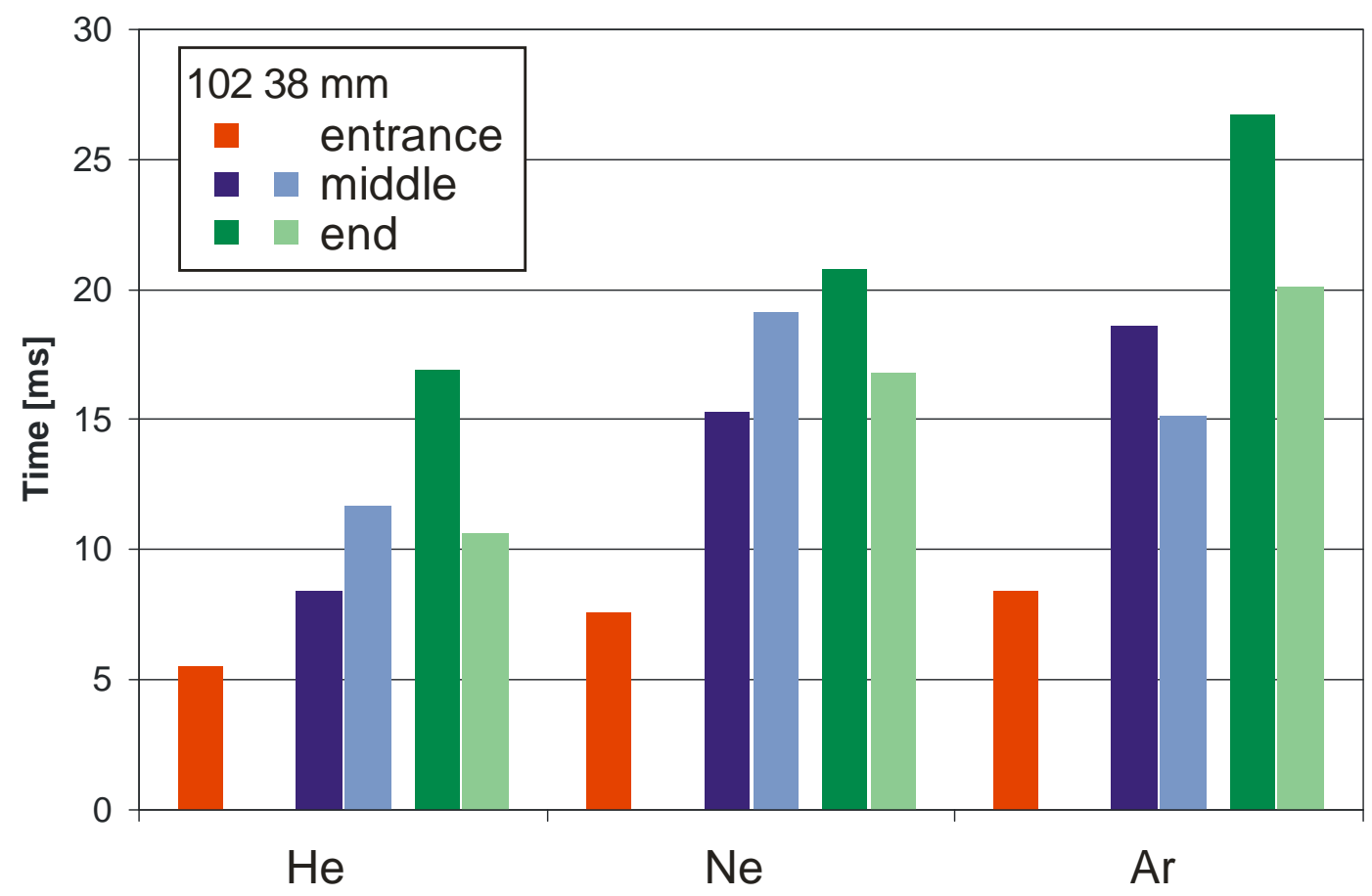

Fig. 22: Time required for $50 \%$ of the gas to pass the different locations for $\mathrm{He}$, Ne and Ar. The delay $\mathrm{t}_{0}$ until the first gas arrives has been subtracted. 


\section{Table 1}

Velocity during the stationary phase and velocities from Pitot tube analysis: 38 mm tube:

Ar: $\quad v_{\text {eff }}=133 \mathrm{~m} / \mathrm{s}$

$$
\begin{aligned}
& \mathrm{V}_{\text {Pitot }}=160 \mathrm{~m} / \mathrm{s} \\
& \mathrm{V}_{\text {Pitot }}=220 \mathrm{~m} / \mathrm{s} \\
& \mathrm{V}_{\text {Pitot }}=520 \mathrm{~m} / \mathrm{s}
\end{aligned}
$$

Ne: $\quad V_{\text {eff }}=187 \mathrm{~m} / \mathrm{s}$

He: $\quad v_{\text {eff }}=481 \mathrm{~m} / \mathrm{s}$

\section{2 mm tube:}

Ar: $\quad \mathrm{v}_{\mathrm{eff}}=394 \mathrm{~m} / \mathrm{s}$

$\mathrm{v}_{\text {Pitot }}=370 \mathrm{~m} / \mathrm{s}$

Ne: $\quad v_{\text {eff }}=627 \mathrm{~m} / \mathrm{s}$

$\mathrm{V}_{\text {Pitot }}=520 \mathrm{~m} / \mathrm{s}$

He: $\quad v_{\text {eff }}=917 \mathrm{~m} / \mathrm{s}$

$\mathrm{v}_{\text {Pitot }}=980 \mathrm{~m} / \mathrm{s}$ 